\title{
The Weather Hazards Associated with the US-Bangla Aircraft Accident at the Tribhuvan International Airport, Nepal
}

\author{
Greema Regmi, ${ }^{a}$ Sajan Shrestha, Sangeeta Maharjan, Anil Kumar Khadka, \\ RAM PRASAD REgMI, AND GOPI CHANDRA KAPHLE \\ National Atmospheric Resource and Environmental Research Laboratory, Central Department \\ of Physics, Tribhuvan University, Kathmandu, Nepal
}

(Manuscript received 3 September 2019, in final form 11 May 2020)

\begin{abstract}
Safe flights over the Tribhuvan International Airport (TIA), Kathmandu, Nepal, remain a considerable challenge. Since the airport opened, there have been 13 aircraft accidents during landings and takeoffs that have claimed 392 lives. A detailed understanding and dependable forecast of atmospheric conditions that may develop over the complex terrain of the midhills of central Nepal Himalaya are yet to be achieved. The present study discusses the near-surface atmospheric conditions possibly associated with the most recent fatal crash at TIA on 12 March 2018 as revealed by the Advanced Research version of the Weather Research and Forecasting (WRF-ARW) Model routine forecast. At the time of the accident, two prominent gap winds were converging in the valley, thereby, forming a crosswind and a mix of strong up- and downdrafts over the airfield. As a result, the near-surface atmosphere was significantly turbulent. Unexpected encounters with such turbulent winds are a likely contributor to the fatal crash. This indicates that the knowledge of nearsurface atmospheric conditions, critically needed by pilots in advance, for safe operations over the airfield may be generated with WRF-ARW forecasts.
\end{abstract}

\section{Introduction}

The Kathmandu Valley, located in the central Nepal Himalaya, accommodates the only international airport of Nepal, the Tribhuvan International Airport (TIA) (see Fig. 1a). The complexity of the topological floor of the valley creates atmospheric dynamics that can be difficult for aircraft to negotiate. One result is that the TIA is among the most difficult international airports to safely use. Since its establishment in 1946, the TIA has witnessed 13 aircraft accidents, 9 of which claimed 392 lives (Civil Aviation Authority of Nepal 2018). Two of the fatal accidents occurred during landing, three during the takeoff, and five accidents involved collisions with nearby hills. Nonfatal accidents involved the aircraft either skidding or overrunning the runway. Details of these aircraft incidents are summarized in Table 1 . The flight UBG-211 crash on 12 March 2018 is the most recent fatal accident over the TIA airfield, and it is the subject of the present

\footnotetext{
${ }^{a}$ Current affiliation: Department of Physics, St. Xavier's College, Kathmandu, Nepal.
}

Corresponding author: Sajan Shrestha, pclsajan@gmail.com study. According to the Accident Investigation Commission (DHC-8-402; S2-AGU) 2018, hereafter AIC (2018), the flight UBG-211, a Bombardier aircraft operated by USBangla Airlines that was carrying 71 people crashed while landing at the TIA (see Fig. 1b) killing 51 people on board.

The frequent occurrence of accidents in and around the TIA during periods of atmospheric instability suggests that safe aircraft operation is particularly challenging, especially during landing and takeoff (LTO). Atmospheric instability is exacerbated by the topographic complexity of the central Nepal Himalaya and the meteorological conditions that develop over the Kathmandu Valley (Regmi et al. 2003; Regmi and Maharjan 2015). During LTO procedures, an aircraft is most vulnerable to ground impact and only a few seconds are available to a pilot to recover lost control (McCann 1999). Early knowledge of low-level meteorological adversities over the TIA is a critical component for improved flight safety.

A few offline numerical forecast studies reported for Nepalese skies have revealed a correlation of aircraft accidents with unstable meteorological conditions (Regmi 2014a,b; Regmi et al. 2017). The Nepal Army's Britten 

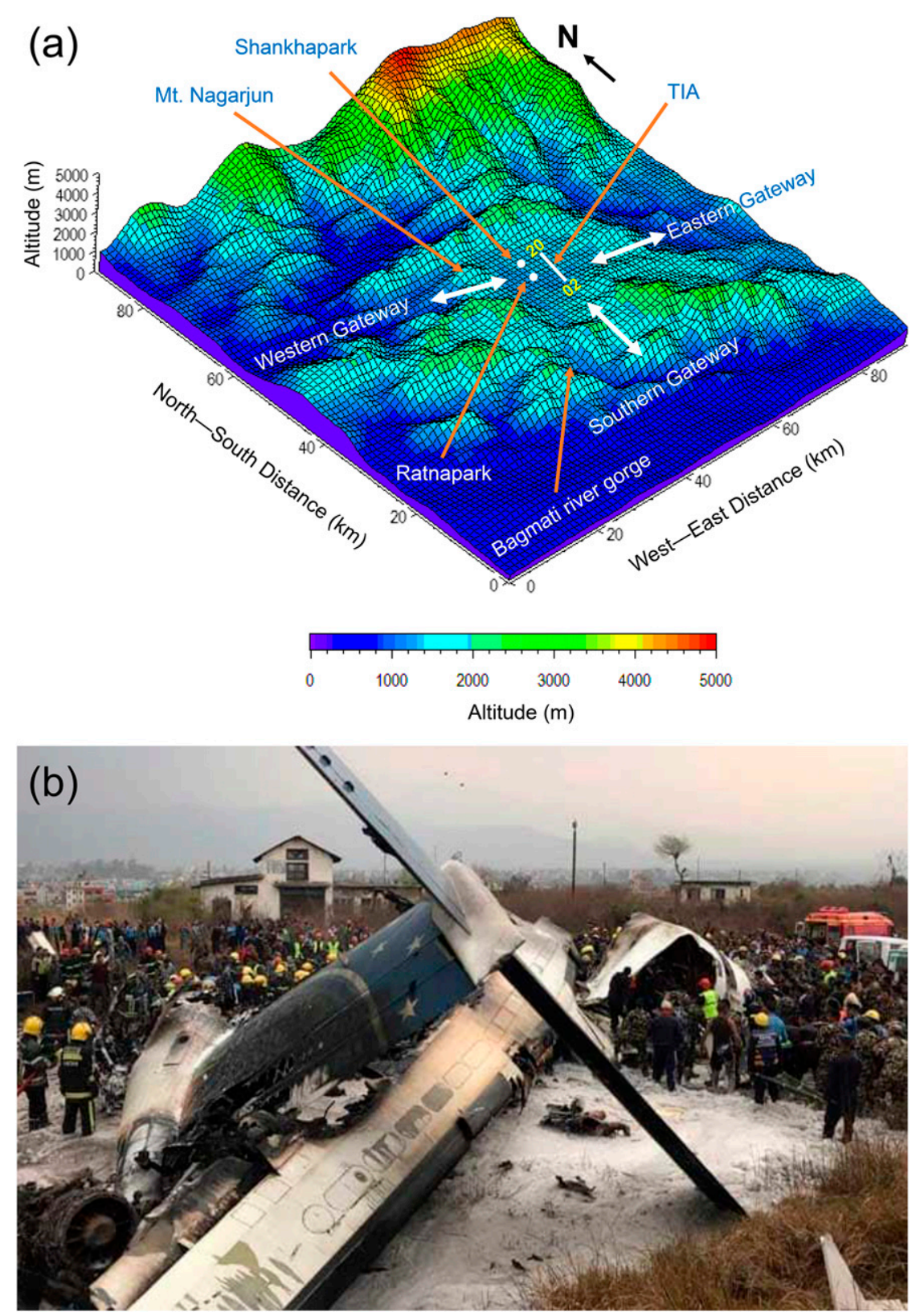

FIG. 1. (a) The bird's-eye view of the Kathmandu Valley and (b) the US-Bangla aircraft (UBG211) after the accident at the Tribhuvan International Airport in Kathmandu. [Source for (b): https:// www.ndtv.com/world-news/plane-from-bangladesh-crashes-at-nepals-kathmandu-airport-1822772. Both " 02 " and " 20 " in (a) are the southern and northern end of the runway at TIA.]

Norman BN-2 Islander crash in Bowang of western Nepal (Regmi 2014a) and the Nepal Airlines DHC6/300 Twin Otter 9N-ABO crash at Jomsom Airfield (Regmi 2014b) were attributed to strong downdrafts and lowlevel turbulence. Similarly, the Nepal Airlines DHC6/300 Twin Otter $9 \mathrm{~N}-\mathrm{ABB}$ crash at Mt. Masina Lek was accompanied by series of meteorological adversities: low-level cloud ceiling, supercooled cloud water, hail, trapped mountain waves, supercritical descent of a strong tailwind, and the development of turbulence at the altitude of the flight path (Regmi et al. 2017).

A close examination of the past meteorological studies over the Kathmandu Valley carried out for air pollution transport modeling purposes (Regmi et al. 2003, 2019; Panday et al. 2009); and for understanding the trapped mountain-wave excitation over the southern mountain rim of the valley (Regmi and Maharjan 2015) reveal that the near-surface airflow over the valley can 


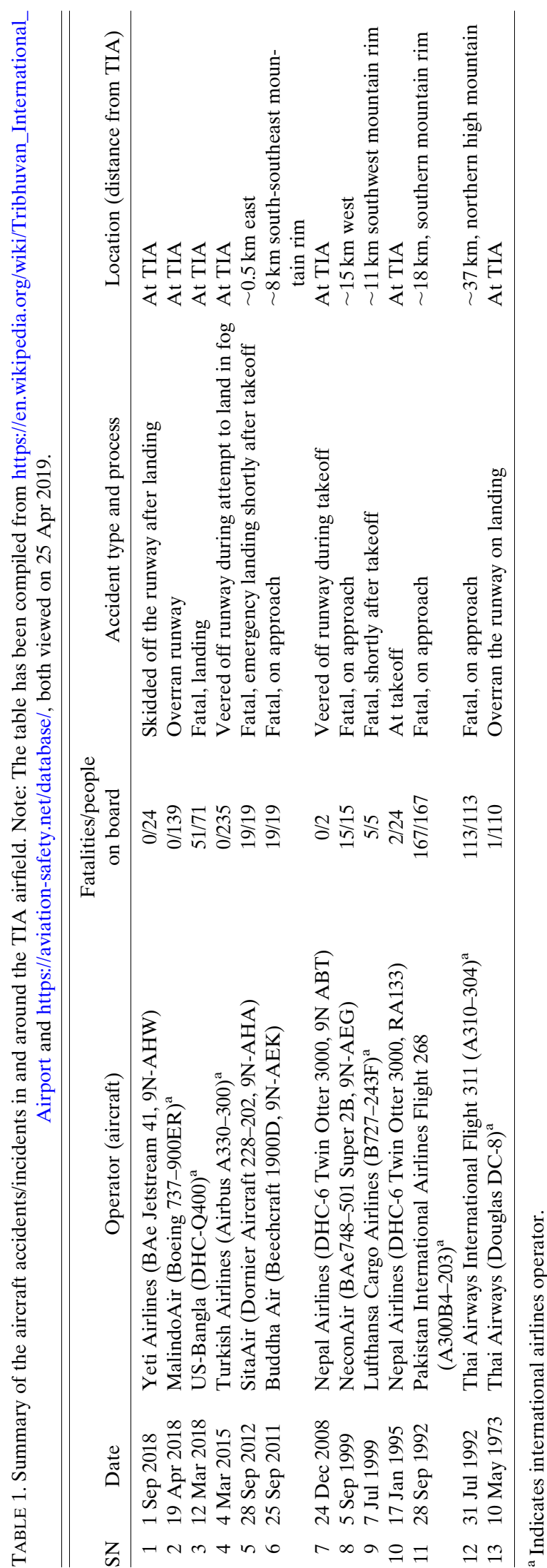

pose significant challenges for safe air operations. These include:

- Two major wind systems of the valley, that is, relatively cooler southwesterly and warmer northwesterly winds, intrude into the valley at about 1200 LST via southern and western low-mountain passes, which also serve as gateways (international and domestic, respectively) to the Kathmandu Valley for aircraft.

- During the afternoon, the southwesterly and northwesterly wind systems merge into a westerly over the central area of the valley and channel into the eastern neighboring valley via a low-mountain pass (eastern gateway). The TIA airfield generally suffers convergence of the two major wind systems and the mild westerly crosswind.

- Later in the afternoon, a relatively warm northwesterly wind makes a hydraulic jump over the western part of the valley and rides over the shallow, relatively cold southwesterly wind (Regmi et al. 2003, 2019).

- A low-level trapped mountain-wave excitation may occur over the southern gateway of TIA from early evening until late morning (Regmi and Maharjan 2015).

The meteorological complexity of the Kathmandu Valley is further complicated by the occasional massive accumulation of cold air around the valley that generates a large-scale gravity current that travels more than $200 \mathrm{~km}$ toward western Nepal. It was also linked with the fatal accident at Mt. Masina Lek (Regmi et al. 2017).

However, no studies found reported addressing the flight risks associated with near-surface atmospheric conditions, particularly, the generation of ground level turbulence, over the TIA airfield. Moreover, advance or real-time numerical weather forecast products for aviation safety are not available for the airport. The pilots are deprived of the knowledge of the spatiotemporal distribution of the near-surface atmospheric conditions they would critically need in advance for safe operation. This situation might have played a considerable role in the number of incidences in and around the airport. Very recently, National Atmospheric Resource and Environmental Research Laboratory (NARERL) at Tribhuvan University has taken an initiative to fill this gap by performing a high-resolution routine numerical weather forecast for Central Nepal using the WRF-ARW modeling system (Skamarock et al. 2008).

This paper utilizes the WRF-ARW routine forecast at NARERL to discuss the spatiotemporal distribution of the near-surface atmospheric conditions and explores their association with the fatal crash of the UBG-211 at the TIA airfield on 12 March 2018. The ground-level turbulence generation over the TIA airfield and its impact on the aircraft landing is of particular interest. 

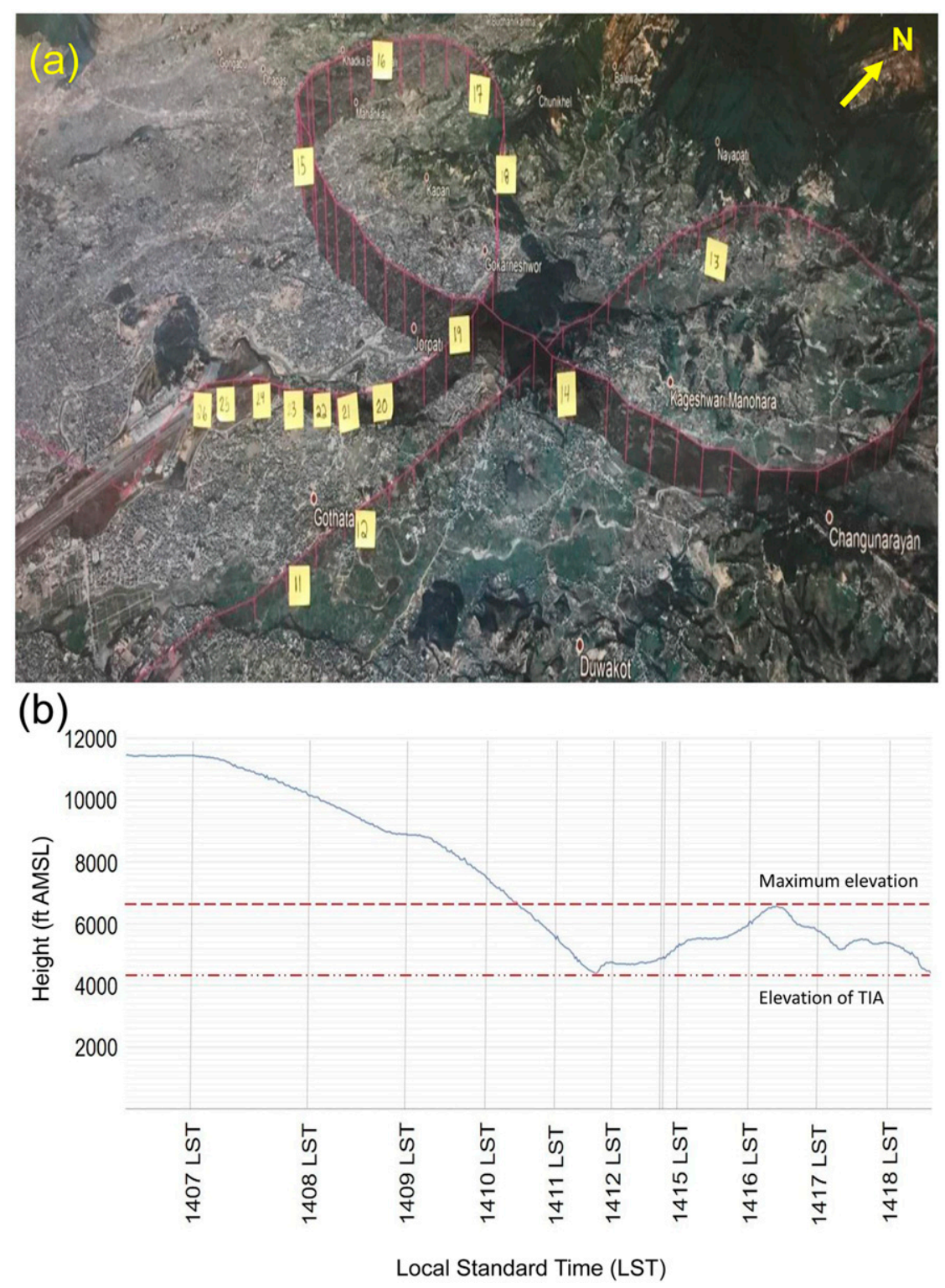

FIG. 2. (a) Flight path of UBG-211 extracted from the DFDR and plotted on a Google Earth image (AIC 2018) and (b) time series of last minute flight altitude of UBG-211 over the Kathmandu Valley. In (a) the number tags represent the location of contact made between the UBG-211 and control tower at the TIA. In (b) the red dash-dotted line at the bottom represents the elevation of the TIA and the red dashed line at the top represents the maximum altitude attended by the aircraft during its hold in the Kathmandu Valley. The time axis has been converted to LST while it was in UTC in the source: https://twitter.com/flightradar24/ status/973130937553780736 (viewed on 25 Apr 2019).

By this, it also aims to demonstrate that the early prediction of ground level hazards may be possible to a degree of accuracy that can aid safe LTOs at the airport.

\section{US-Bangla (UBG-211) flight history}

This section presents a brief flight history of the UBG211 on its flight to Kathmandu that may help understand the connection between the forecast weather pattern and the accident. Figure 2 is a graphic illustration of the final portion of the UBG-211 flight path adopted from the Accident Investigation Commission Final Report (DHC-8-402; S2-AGU).

The scheduled flight of the UBG-211, a DHC-Q400 Bombardier turboprop, having maximum takeoff mass of $29257 \mathrm{~kg}$ took off from Hazrat Shahjalal International 
Airport, Dhaka, at 0651:40 UTC to land at TIA at 0830 UTC (1415 LST). The aircraft was designated to land at runway "02" for the southerly approach. The aircraft entered the Kathmandu Valley via the southern gateway and prepared to land under reportedly normal meteorological conditions; mild westerly surface crosswinds of 7 $8 \mathrm{kt}\left(3.60-4.12 \mathrm{~m} \mathrm{~s}^{-1}\right)$, visibility of around $6 \mathrm{~km}$ and the sky covered with scattered clouds at low and high levels. The flight did not successfully align its approach. It deviated around $2 \mathrm{~km}$ east and flew parallel to the runway at a height of only $300 \mathrm{ft}(\sim 91.44 \mathrm{~m})$ above ground level (AGL) (see Fig. 2) toward the northeast. The control tower had to alert the cabin crew that they were heading toward runway 20 for the northerly approach. The path retrieved from the digital flight data recorder (DFDR) (see Fig. 2a) suggests that the UBG-211 made a right round near the mountain in the northeastern part of the valley, then headed to the west and continued to maneuver making another round over the northwestern part. At one point, the aircraft dropped to such a low altitude that it nearly contacted the ground (see Fig. 2a). The maximum elevation attended by the UBG-211 during its hold over the valley was approximately $6600 \mathrm{ft}(\sim 1629 \mathrm{~m})$ above mean sea level (MSL) (see Fig. 2b) while the elevation of the TIA is $4390 \mathrm{ft}(\sim 1338 \mathrm{~m})$ MSL. During much of this portion of the flight, the aircraft altitude was less than $300 \mathrm{~m}$ AGL. In its final approach, the pilot-in-charge (PIC) attempted to land on runway 20 aligning the plane to the runway while it was still heading west but passed by few tens of meters. On missing the runway the pilot attempted a realignment, making a sharp left turn with bank angle up to $40^{\circ}$. Reportedly the plane was shaking violently before touching the ground. The flight touched down $1700 \mathrm{~m}$ past the threshold of runway 02 where it skidded off to the east, hit the airfield perimeter fence, and was subsequently engulfed in fire. The AIC (2018) reports the lack of situational awareness of pilot amid much confusion between the PIC and air traffic controller (ATC) in the TIA tower to be the cause for the accident.

\section{Forecast setup and initialization}

This study was realized by analyzing the routine forecast products of the WRF-ARW modeling system (Skamarock et al. 2008) and by performing a series of offline WRF-ARW sensitivity tests with different global data and physics parameterizations.

\section{a. Routine forecast setup and initialization}

The NARERL routinely performs 72 -h weather forecasts using the WRF-ARW modeling system for the central Nepal region. The WRF-ARW modeling system provides operational weather forecasting in more than four dozen countries and is in use by more than 36000 people from 162 countries (Powers et al. 2017). The effectiveness of the model to address diverse atmospheric conditions over complex Himalayan terrains (Collier and Immerzeel 2015; Karki et al. 2017; Barros et al. 2018; Regmi et al. 2017, 2019; Regmi and Maharjan 2015) demonstrates the aptness of using the WRF-ARW modeling system for this region.

The NARERL has configured the WRF-ARW modeling system version 3.5.1 for three day forecast with 15-min output history. The forecast is updated every day. For each of the 3-day runs, the period of first $24 \mathrm{~h}$, from 0000 UTC (0545 LST) of the first day to 2345 UTC (0530 LST) of the next day, is considered as spinup period and the second 24-h output is used for the analysis. The simulation domain system consists of a triply nested two-way interacting mesh each with $91 \times 91$ horizontal and 35 vertical grid points with a model top set at $50 \mathrm{hPa}$. The coarse domain (D1), fine domain (D2), and the finest domain (D3) are all centered at the center of the Kathmandu Valley $\left(27.7^{\circ} \mathrm{N}, 85.3^{\circ} \mathrm{E}\right)$ and, respectively, are set at 9-, 3-, and 1-km horizontal grid resolution. The finest domain covers the Kathmandu Valley and its immediate surroundings (see Fig. 3).

The Global Forecasting System (GFS) generated meteorological data at $0.25^{\circ} \times 0.25^{\circ}$ resolution issued for every three hours by National Centers for Environmental Prediction (NCEP) and the 24 categories land use and 30-s terrain elevation data of the U.S. Geological Survey (USGS) are used to initialize the WRF-ARW Model. No data assimilation is performed.

As for the physics parameterization options, the routine forecast uses the Thompson graupel scheme (Thompson et al. 2004) for microphysics, the RRTM scheme (Mlawer et al. 1997) for longwave radiation, the Dudhia scheme (Dudhia 1989) for shortwave radiation, the MYJ scheme (Janjić 2001) for the planetary boundary layer, and the Noah land surface model (Chen and Dudhia 2001). Table 2 summarizes the details of the model configuration and initialization.

\section{b. Sensitivity test setup and initialization}

A deterministic numerical weather forecast tends to have large uncertainty due to errors associated with the global initial conditions during initialization of the model, poor representation of subgrid-scale terrain features and physical processes in parameterization schemes, inadequate grid resolution, etc.

To demonstrate the range of uncertainties in the NARERL's routine forecasts and conclusions based on them, three 6-day-long (9-15 March 2018) model sensitivity simulations were performed with different turbulence resolving planetary boundary layer (PBL) 


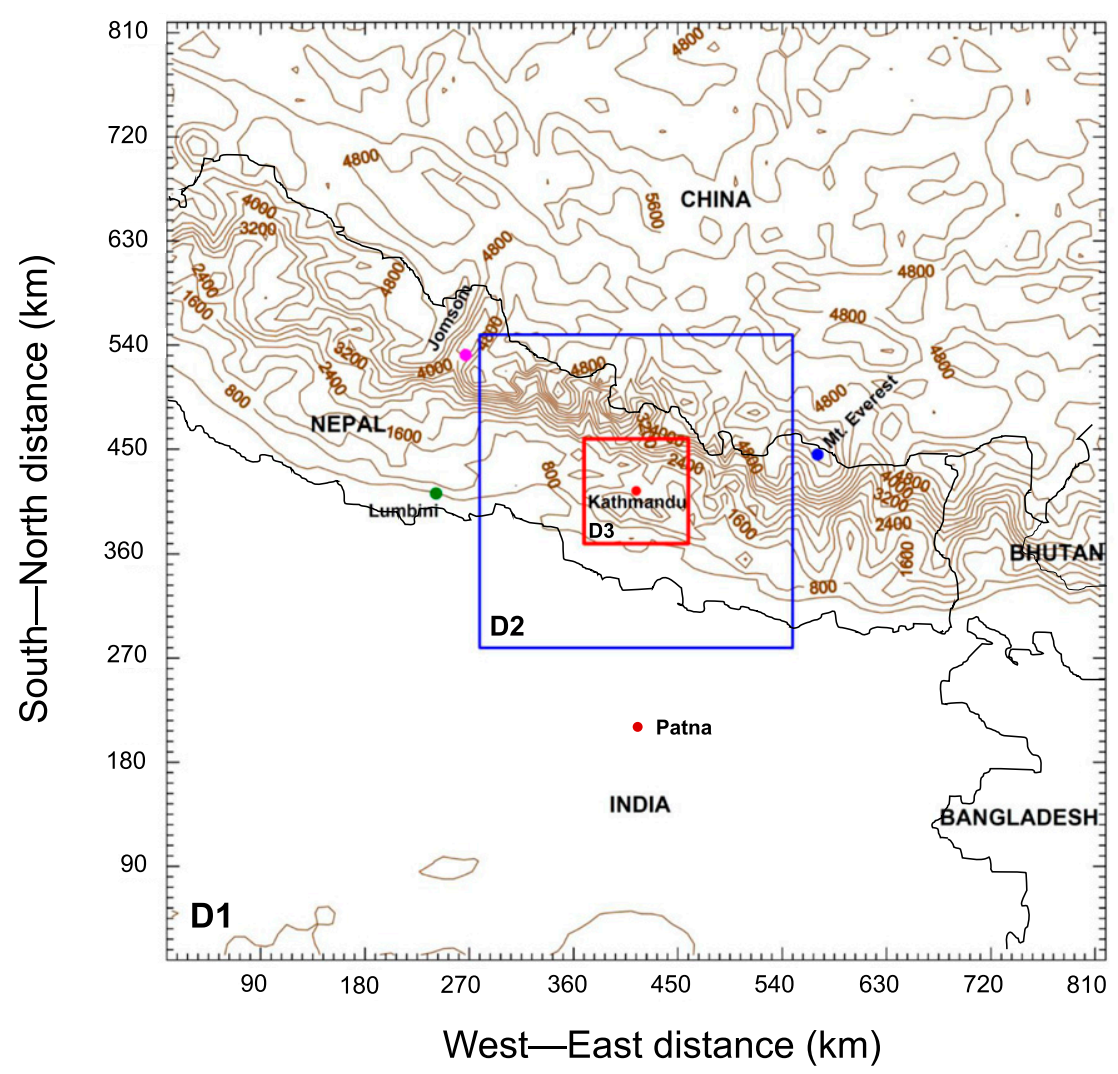

FIG. 3. Triply nested simulation domains centered at $27.7^{\circ} \mathrm{N}, 85.3^{\circ} \mathrm{E}$ configured for WRF-ARW run. The locations of Kathmandu, Lumbini, Jomsom, Mount Everest, and Patna are indicated with colored bullet points.

parameterization schemes (viz., BouLac, MYNN2, and QNSE) available in WRF version 3.5.1. The BouLac, MYNN2, and QNSE including the MYJ use the 1.5-order local turbulence closure parameterization schemes and provide both the turbulence kinetic energy and eddy length to calculate the eddy dissipation rate (EDR) used herein to describe the turbulence in and around the Kathmandu Valley. The PBL parameterization scheme sensitivity was particularly selected for the purpose, as they are found to influence the model's representation of buoyancy and vertical wind shear (Hong et al. 2006; Cohen et al. 2015) and thus, the generation and dissipation of boundary layer turbulence.

In addition to the three PBL sensitivity experiments, an additional hindcast simulation was performed initialized with the ECMWF Reanalysis Interim (ERA-I) global data from European Centre for Medium-Range Weather Forecasts (ECMWF) with the same model configuration used for the routine forecast that uses MYJ PBL scheme. This particular experiment was performed to inspect if the global input data from ECMWF would result in better forecasts for this region. It may also serve to demonstrate the uncertainties in the forecast in using different global input datasets. Furthermore, the grid resolution sensitivities were also checked by performing a comparative analysis of the uncertainty between the fine domain (D2) at $3 \mathrm{~km}$ and the finest domain (D3) at 1-km horizontal grid resolution in the routine forecast data. Sensitivity experiments are summarized in Table 3.

\section{Results}

This section describes the rationale of the routine forecast with respect to the available observations and sensitivity tests and then proceeds with the discussion of the spatial and temporal characteristics of the meteorological fields related to the UBG-211 accident.

\section{a. Rationale of the forecast}

To evaluate the consistencies and accuracy of the forecast developed by the WRF-ARW Model, the predicted values of temperature, relative humidity, wind speed, and wind direction were compared with the recorded meteorological observations. Weather records of the automatic weather station at the TIA and the 
TABLE 2. WRF Model setup and configuration used in the study.

\begin{tabular}{lc}
\hline \multicolumn{1}{c}{ Physics/domain design } & Parameterizations used \\
\hline WRF Model version & 3.5 .1 \\
Domain system & Triply nested two-way interacting \\
Domain center & $27.7^{\circ} \mathrm{N}, 85.3^{\circ} \mathrm{E}$ \\
Horizontal resolution & $9 \mathrm{~km} \times 3 \mathrm{~km} \times 1 \mathrm{~km}$ \\
Terrain resolution & $5 \mathrm{~min} \times 30 \mathrm{~s} \times 30 \mathrm{~s}$ \\
Horizontal grid points & $91 \times 91$ \\
Vertical grid points & 35 \\
Model top & $50 \mathrm{hPa}$ \\
Microphysics & Thompson graupel scheme \\
Longwave radiation & RRTM \\
Shortwave radiation & Dudhia scheme \\
Land surface model & MYJ \\
Planetary boundary layer & GFS \\
Boundary data & 24-category USGS \\
Land use & 0000 UTC 9 Mar 2018 \\
Start date & 0000 UTC 15 Mar 2018 \\
End date & 15 min \\
Output history interval & \\
\hline
\end{tabular}

two air quality monitoring stations at Ratnapark and Shankhapark were available for the purpose (see Fig. 1 for location). Though limited and uncoordinated surface observation data were available, the resemblance of observed diurnal weather patterns with the WRF-ARW forecasts (see Figs. 4a-1) and their corresponding scatterplots (see Figs. $4 a^{\prime}-\mathrm{l}^{\prime}$ ) suggests a reasonable reproduction of diurnal variation of prevailing surface level meteorological situations on the day of the accident. The magnitude, especially of relative humidity, wind speed, and direction, however, show larger discrepancies to the observation. Visual inspection of the 4-h time window (1200-1600 LST; see black rectangle in Fig. 4) during the accident time ( $\sim 1415$ LST) in Figs. 4a-1, however, may suggest that the meteorological conditions are relatively better captured during the time of the accident.

For the quantitative analysis of the model's performance, linear regression and bias analysis of the measured and forecast datasets from the three locations were performed to compute the correlation coefficient $(R)$, mean bias $(\mathrm{MB})$, and the normalized mean bias factor $\left(B_{\mathrm{NMBF}}\right)$ (Yu et al. 2006).

The correlation coefficient $R$ gives the degree of linear relationship between two variables, and here, indicates reproduction of the observed diurnal pattern. Its value ranges from -1 to 1 , where a value of 0 suggests no relation and $R$ close to $1(-1)$ suggests perfect positive (negative) linear relation between the variables. For wind direction, as it is a circular variable, a circular correlation coefficient $r_{c}$ described in Eq. (1) (Jammalamadaka and Sengupta 2001) was used:

$$
r_{c}=\frac{\sum_{i=1}^{N} \sin \left(M_{i}-\bar{M}\right) \sin \left(O_{i}-\bar{O}\right)}{\sqrt{\sum_{i=1}^{N} \sin ^{2}\left(M_{i}-\bar{M}\right) \sum_{i=1}^{N} \sin ^{2}\left(O_{i}-\bar{O}\right)}} .
$$

In Eq. (1), $O_{i}$ is the measured value, $M_{i}$ is the predicted value, $\bar{O}$ is the mean of the observation, and $\bar{M}$ is the mean of the model forecast for a set of $N$ paired data.

$\mathrm{MB}$ and $B_{\mathrm{NMBF}}$ provide, respectively, the average of the bias $\left(M_{i}-O_{i}\right)$ of individual pairs of observed and forecast data and the factor of relative measure of bias from the observation. As the absolute deviation of wind direction cannot be more than $180^{\circ}$, modified bias given in Eq. (2) (Mughal et al. 2017) could be more appropriate to calculate the $\mathrm{MB}$ and $B_{\mathrm{NMBF}}$ instead of simply $M_{i}-O_{i}$

$$
\begin{aligned}
\operatorname{bias}= & \left(M_{i}-O_{i}\right)\left|\left[1-\left(\frac{360}{\left|M_{i}-O_{i}\right|}\right)\right]\right|, \quad \text { if } \\
& \left|M_{i}-O_{i}\right|>180, \\
B_{\mathrm{NMBF}}= & \frac{\sum\left(M_{i}-O_{i}\right)}{\sum O_{i}}=\frac{\bar{M}}{\bar{O}}-1, \text { for } \bar{M}>\bar{O}, \\
= & \frac{\sum\left(M_{i}-O_{i}\right)}{\sum M_{i}}=1-\frac{\bar{O}}{\bar{M}}, \text { for } \bar{O}>\bar{M},
\end{aligned}
$$

where $\mathrm{MB}$ and $B_{\mathrm{NMBF}}$ are unbounded (i.e., its value ranges from $-\infty$ to $+\infty$ ). A positive (negative) value of $B_{\mathrm{NMBF}}$ implies that the forecast overestimates (underestimates) the observation by the factor of $B_{\mathrm{NMBF}}+$ $1\left(1-B_{\mathrm{NMBF}}\right)$.

Similarly, for uncertainties in the prediction and its relative measure, mean absolute error (MAE) and normalized meanabsolute error factor $\left(E_{\mathrm{NMAEF}}\right)$

TABLE 3. Sensitivity experiment setup. All the model setup besides that mentioned in the table are the same as the routine forecast presented in Table 2 .

\begin{tabular}{clccc}
\hline \hline SN & Simulation & Global initialization data (source) & PBL scheme (WRF option) & Surface layer scheme (WRF option) \\
\hline 1 & Routine forecast & GFS (NCEP) & MYJ (2) & Monin-Obukhov (Janjić Eta) scheme (2) \\
2 & Hindcast & GFS (NCEP) & QNSE (4) & QNSE (4) \\
3 & Hindcast & GFS (NCEP) & MYNN2 (5) & Monin-Obukhov (Janjić Eta) scheme (2) \\
4 & Hindcast & GFS (NCEP) & BouLac (8) & Monin-Obukhov (Janjić Eta) scheme (2) \\
5 & Hindcast & ERA-I (ECMWF) & MYJ (2) & Monin-Obukhov (Janjić Eta) scheme (2) \\
\hline
\end{tabular}




\section{$\underline{\text { Ratnapark }}$}

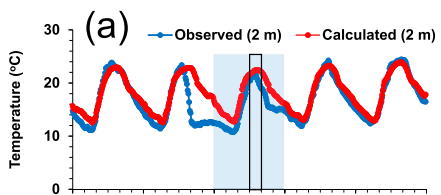

(b) $\rightarrow$-observed $(2 \mathrm{~m}) \rightarrow$ - Calculated $(2 \mathrm{~m})$
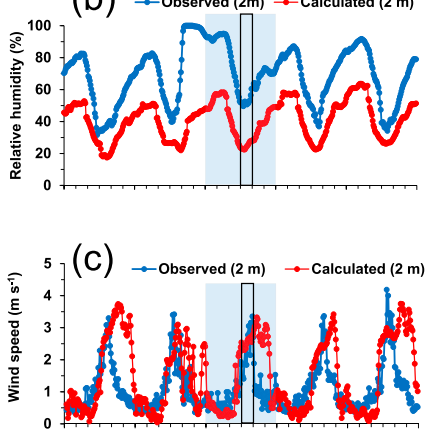

(d)

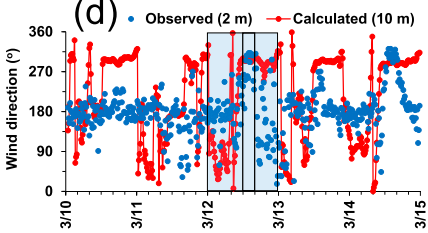

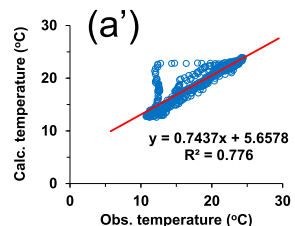

(b')
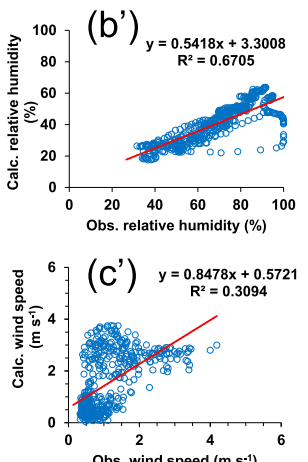

(d') $y=0.3731 x+148.0$

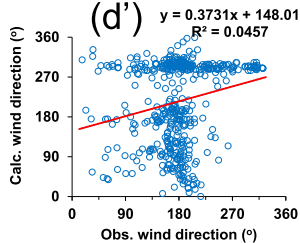

\section{Shankhapark}
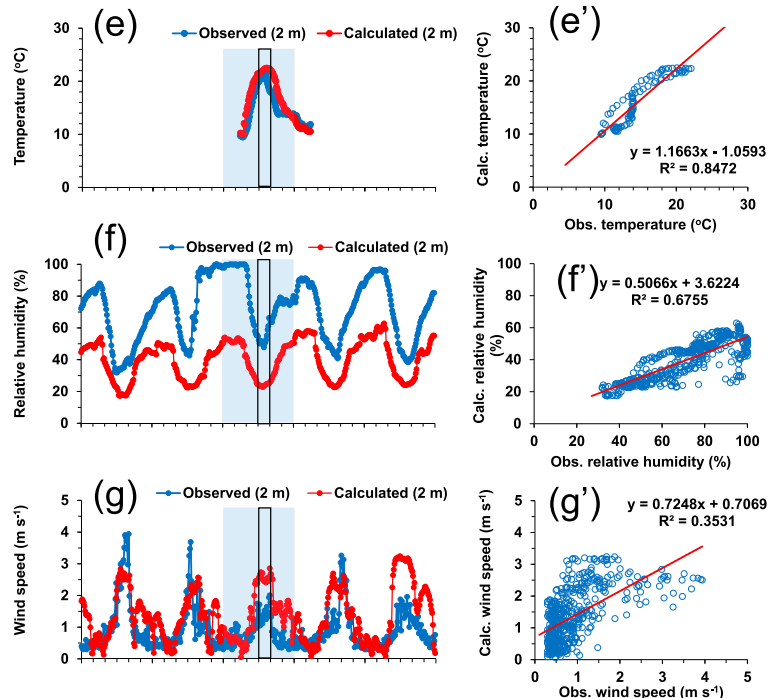

(h)
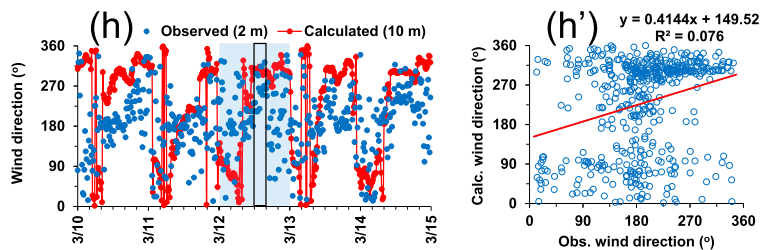

\section{$\underline{\text { Tribhuvan International Airport }}$}
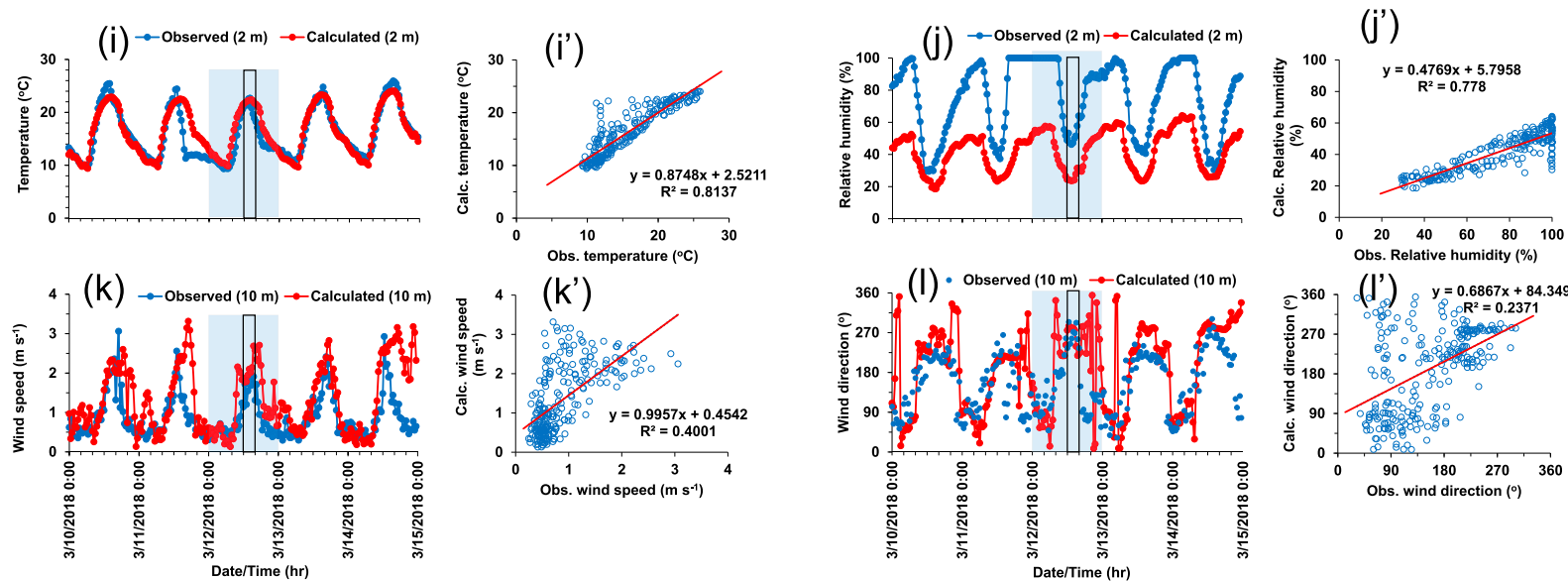

FIG. 4. The comparison between observed and WRF-ARW forecasted temperature, relative humidity, wind speed, and wind direction at (a)-(d) Ratnapark, (e)-(h) Shankhapark, and (i)-(l) the Tribhuvan International Airport (see Fig. 1a for location). ( $\left.\mathrm{a}^{\prime}\right)-\left(\mathrm{l}^{\prime}\right)$ The corresponding scatter diagrams for (a)-(1). The shaded region in (a)-(l) represents the day of the accident of the UBG-211 aircraft. The black rectangle marks the time 1200-1600 LST 12 Mar 2018.

(Yu et al. 2006) were calculated for the four meteorological parameters with formulations given in Eqs. (4) and (5), respectively. MAE is the average of the absolute error $\left(\left|M_{i}-O_{i}\right|\right)$ and $E_{\mathrm{NMAEF}}$ is the fraction of MAE and the mean observation. The value of MAE and $E_{\mathrm{NMAEF}}$ ranges between 0 and $+\infty$. Values of 0 or closer suggest less error and larger values imply larger error. For wind direction, $\left|M_{i}-O_{i}\right|\left|\left[1-\left(360 /\left|M_{i}-O_{i}\right|\right)\right]\right|$, if $\left|M_{i}-O_{i}\right|>180$, may be used instead of $\left|M_{i}-O_{i}\right|$ like in the case of $\mathrm{MB}$ and $B_{\mathrm{NMBF}}$ :

$$
\mathrm{MAE}=\frac{\sum\left|M_{i}-O_{i}\right|}{N},
$$


TABLE 4. Correlation coefficient, mean observed value, and mean predicted value, mean bias, normalized mean bias factor, mean absolute error, and normalized mean absolute error factor calculated between the observed and WRF-ARW forecast.

\begin{tabular}{|c|c|c|c|c|c|c|c|}
\hline & $R$ & $\bar{O}$ & $\bar{M}$ & MB & $B_{\mathrm{NMBF}}$ & MAE & $E_{\mathrm{NMAEF}}$ \\
\hline Temperature & 0.89 & 16.21 & 17.34 & 1.13 & 0.07 & 1.56 & 0.10 \\
\hline Relative humidity & 0.83 & 71.60 & 40.72 & -30.88 & -0.76 & 30.88 & 0.76 \\
\hline Wind speed & 0.58 & 0.98 & 1.41 & 0.43 & 0.44 & 0.67 & 0.68 \\
\hline Wind direction & 0.32 & 178.46 & 214.97 & 31.70 & 0.18 & 77.57 & 0.43 \\
\hline Wind direction (wind speed $>1.5$ ) & 0.4 & 211.92 & 268.95 & 54.83 & 0.26 & 61.71 & 0.29 \\
\hline
\end{tabular}

$$
\begin{aligned}
E_{\mathrm{NMAEF}} & =\frac{\sum\left|M_{i}-O_{i}\right|}{\sum O_{i}}, \text { for } \bar{M}>\bar{O} \\
& =\frac{\sum\left|M_{i}-O_{i}\right|}{\sum M_{i}}, \text { for } \bar{O}>\bar{M} .
\end{aligned}
$$

Dimensionless measures like $R, B_{\mathrm{NMBF}}$, and $E_{\mathrm{NMAEF}}$ help to compare the model's performance on the prediction of the same, as well as different, quantities irrespective of their units. A good prediction, in terms in terms of reliability and accuracy, would have a larger value of $R$ and a smaller value of MB, $B_{\mathrm{NMBF}}$, MAE, and $E_{\mathrm{NMAEF}}$ and vice versa. Table 4 provides the values of $R, \bar{O}, \bar{M}, \mathrm{MB}, B_{\mathrm{NMBF}}, \mathrm{MAE}$, and $E_{\mathrm{NMAEF}}$ calculated by considering observation and forecast at all three stations.

From Table 4 it can be seen that temperature is well correlated with the observation $(R=0.89)$ and is warm biased by $1.13^{\circ} \mathrm{C}$, that is, model, on average, overestimates the observed temperature by the factor of 1.07 $\left(B_{\mathrm{NMBF}}=0.07,1+0.07\right)$. The uncertainty in the forecast is $1.56^{\circ} \mathrm{C}(0.1$ times the mean observation). The relative humidity, on the other hand, showed good correlation but was largely underpredicted as indicated by a negative bias of $30.88 \%$ and $B_{\mathrm{NMBF}}$ of -0.76 . The same magnitude of the MB and MAE, and $B_{\mathrm{NMBF}}$ and $E_{\mathrm{NMAEF}}$ and opposite signs justify that the relative humidity was systematically underpredicted by a factor of $1.76(-0.76-1)$. The underprediction of humidity could be due to poor soil moisture content over the region in the GFS input data. Indeed GFS input data show very dry soil over this region (figure not shown).

In the case of wind speed, the diurnal pattern is captured with $R=0.58$ and on average, positive bias and MAE are around 0.43 and $0.67 \mathrm{~m} \mathrm{~s}^{-1}$, respectively. The $\mathrm{MB}$ of $0.43 \mathrm{~m} \mathrm{~s}^{-1}$ is in the acceptable range (MB $\leq$ $\pm 0.5 \mathrm{~m} \mathrm{~s}^{-1}$ ) as suggested by Emery and Tai (2001). The wind speed is over predicted by the factor of 1.44 , and MAE is 0.68 times the mean observation.

The wind direction appears rather weakly correlated $\left(r_{c}=0.32\right)$ and is biased by $31.70^{\circ}$. Pertaining to the larger uncertainty in wind direction for small wind velocities, similar analysis is done for wind direction when the observed wind speed was more than $1.5 \mathrm{~m} \mathrm{~s}^{-1}$ (Zhang et al. 2013). On doing so, the $r_{c}$ increased from 0.32 to 0.40 and MAE decreased from $77.57^{\circ}$ to $61.71^{\circ}$ showing higher correlation and less uncertainty for higher wind speed. However, the wind direction at higher wind speed appeared more biased $\left(\mathrm{MB}=54.83^{\circ}\right)$.

The poor correlation and large bias and error in the above analysis, especially for wind speed and direction could have been partially contributed by the poor model performance on the heavily cloudy day of 11 March 2018, evident in Figs. 4a-1. Nevertheless, during the time of the accident, both the wind speed and direction appear to be better captured by the forecast.

A poor performance of WRF-ARW for a heavily cloudy situation over the Kathmandu Valley has also been reported (Regmi et al. 2019). We further speculate that the rather positive bias in wind speed and direction could have resulted due to large uncertainty in the observations from these sites as they may not meet the standard and meteorological instrument siting guideline of the World Meteorological Organization (WMO 2018). For example, the meteorological observatory at the TIA is located in tiny open land surrounded by tall trees and buildings, and the air quality stations are located in the urban centers where winds are measured at a height of $2 \mathrm{~m}$ above the ground. Thus, we further examined the rationale of model predictions with satellite observed cloud patterns.

On the day of the accident, the sky of the Kathmandu Valley was observed to be partially cloudy. The Terra MODIS satellite image at 1050 LST (see Fig. 5a) shows some clouds over the surrounding mountain ridge tops of the Kathmandu Valley, whereas the Aqua MODIS satellite image at 1320 LST shows the valley partially covered with few convective clouds (see Fig. 5c). The aviation routine weather report (METAR) recorded 3-4 oktas of low clouds and 12 oktas of cumulonimbus clouds during the time of the accident (AIC 2018).

In the Figs. 5a and 5c, the finest calculation domain of the WRF-ARW simulation is enclosed within the red square. The relative humidity forecast at $625 \mathrm{hPa}$ at 1145 LST closely resembles the cloud pattern captured by the 

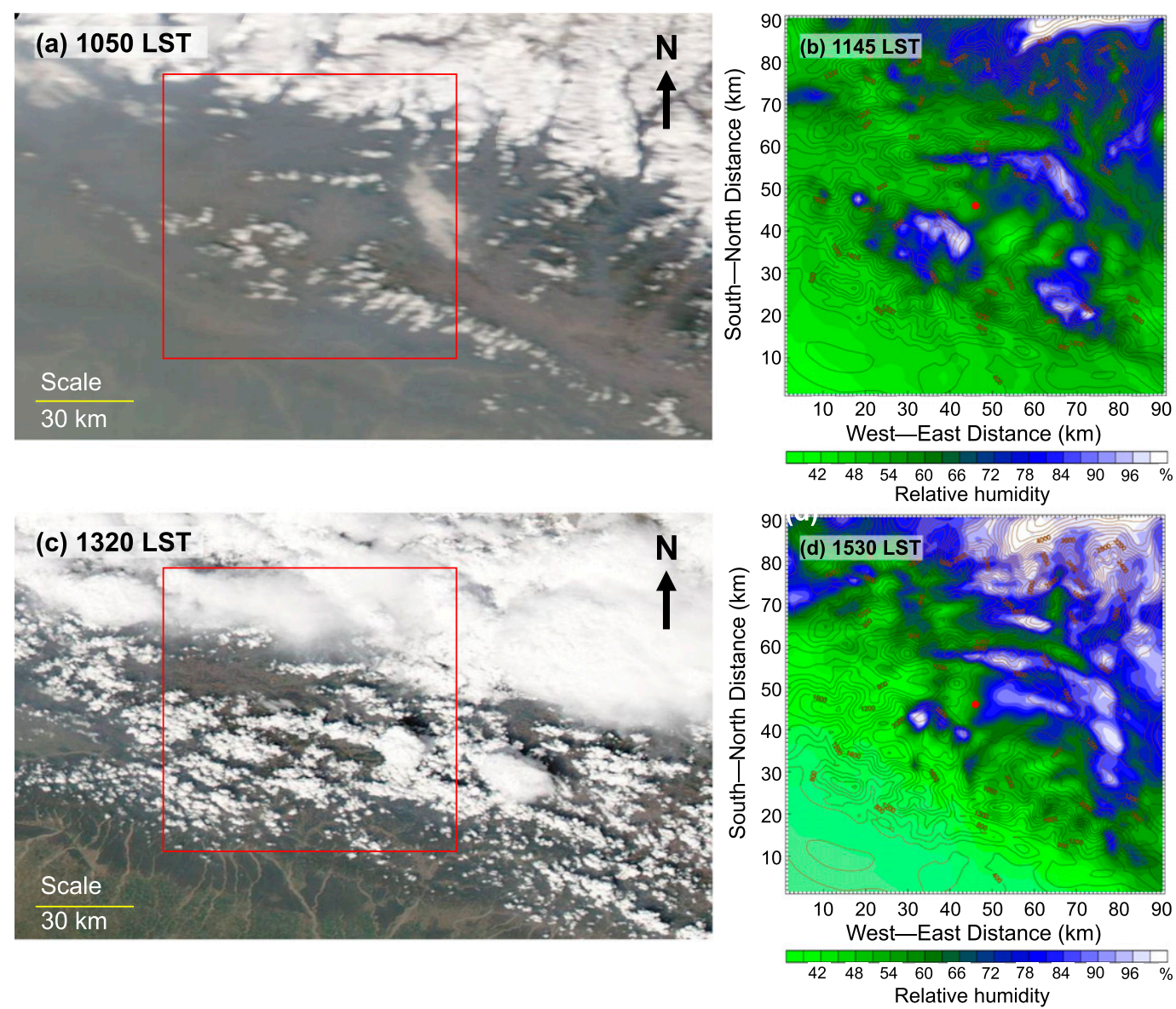

FIG. 5. (a),(c) Satellite images over the Kathmandu Valley taken by Terra MODIS and Aqua MODIS at 1050 and 1320 LST, respectively, 12 Mar 2018. (b),(d) Spatial distribution of relative humidity at $625 \mathrm{hPa}$ over innermost domain at 1400 LST on the same day. The red boxes in (a) and (c) indicate the area covered by the finest simulation domain.

Terra MODIS at 1050 LST (see Figs. 5b,a) and that at 1530 LST with the one captured by Aqua MODIS at 1320 LST (see Figs. 5d,c). This resemblance of relative humidity suggests that the cloud microphysical phenomena in the upper layers were forecast reasonably well. Moreover, the orientation of the cloud (see Figs. 5a,c) signifies the presence of westerly/northwesterly airflow as seen in the forecast at $500 \mathrm{hPa}$ (see Fig. 6b).

In addition, the WRF-ARW forecast of upper air conditions were compared with available radiosonde observations made at Patna, India (see Fig. 3 for location). The strong correlation of the vertical sounding at Patna $\left(25.60^{\circ} \mathrm{N}, 85.10^{\circ} \mathrm{E}\right)$ at 0000 UTC 12 March 2018 and the corresponding model result indicates the forecasted vertical structure of the atmosphere and upper-air meteorological conditions on the day of the accident (see Figs. 6c,d) were not much deviated from reality. The correlation between modeled and observed conditions led us to conclude that the WRF-ARW forecast has captured the prevalent basic meteorological features over the Kathmandu Valley during the UBG-211 accident.

\section{b. Sensitivity of the WRF predictions}

As numerical weather prediction models are sensitive to initial conditions, physics parameterizations, and grid resolution, certain differences in the predictions are generally expected between forecasts using different sets of initial conditions, physics parameterizations, and grid resolution. A forecast that results from a particular set of conditions may be considered reliable, if there appear to be acceptable consistencies with other forecasts that use the different set. To check if the routine forecasts were consistent with each other, four hindcast cases were performed with different turbulence kinetic energy (TKE) PBL schemes and global initialization data (see Table 3).

Figure 7 shows the diurnal variation of temperature, relative humidity, wind speed, wind direction, and EDR predicted at the TIA station in different cases of the sensitivity experiments. In Fig. 7, the WRF-ARW routine 

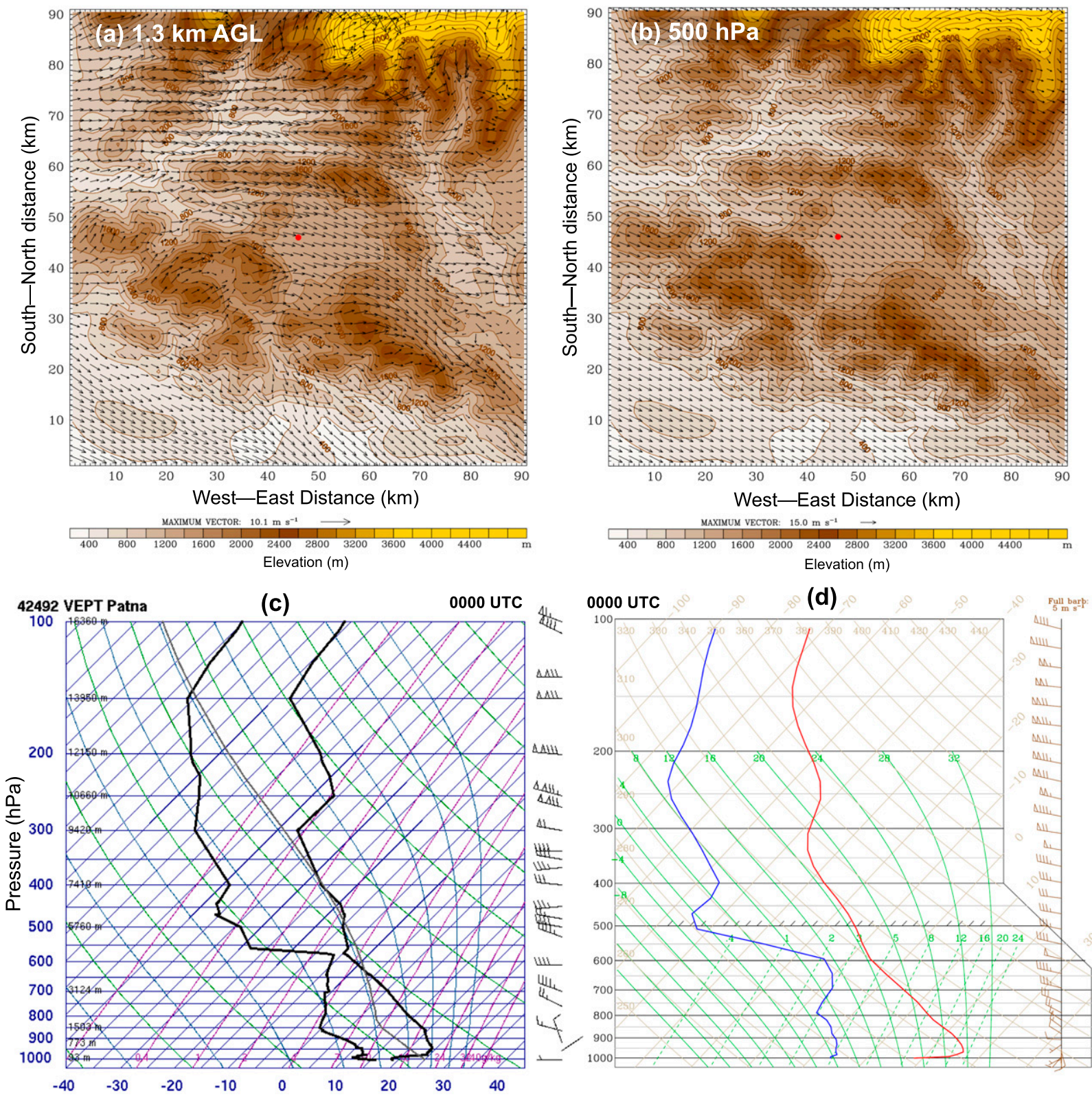

FIG. 6. Spatial distribution of wind over the Kathmandu Valley at (a) $1.3 \mathrm{~km}$ AGL and (b) $500 \mathrm{hPa}$ at $1415 \mathrm{LST}$. (c),(d) The observed and simulated vertical sounding at Patna $\left(25.60^{\circ} \mathrm{N}, 85.10^{\circ} \mathrm{E}\right)$, India. The observed sounding was retrieved from the web database (http:// weather.uwyo.edu/upperair/sounding.html) of the University of Wyoming.

forecast is shown in black lines, observation in red lines with black circles, and others in colored circles mentioned in the legend at the top of the figure. It appears that the routine forecast for the temperature, humidity, and wind direction that uses the MYJ PBL scheme represents their mean characteristics for different PBL schemes used. This might indicate that the routine predictions are reasonable.

The uncertainty analysis, similar to section $4 \mathrm{a}$, has been performed for the hindcast simulations and is presented as a composite bar graph of $R, \mathrm{MB}, B_{\mathrm{NMBF}}$,
MAE, and $E_{\mathrm{NMAEF}}$ in Fig. 8 to aid the comparative analysis of their performance for different meteorological parameters. The values of uncertainty measures for different simulation cases for each variable are grouped. For example, $R$ for temperature for all the cases are grouped, and so is the case for humidity, wind speed and wind direction, and all the cases for the other four factors.

In Figs. 8a, 8c, and 8e large value of $R$ and smaller $B_{\mathrm{NMBF}}$ and $E_{\mathrm{MAEF}}$ suggest the WRF performed better 

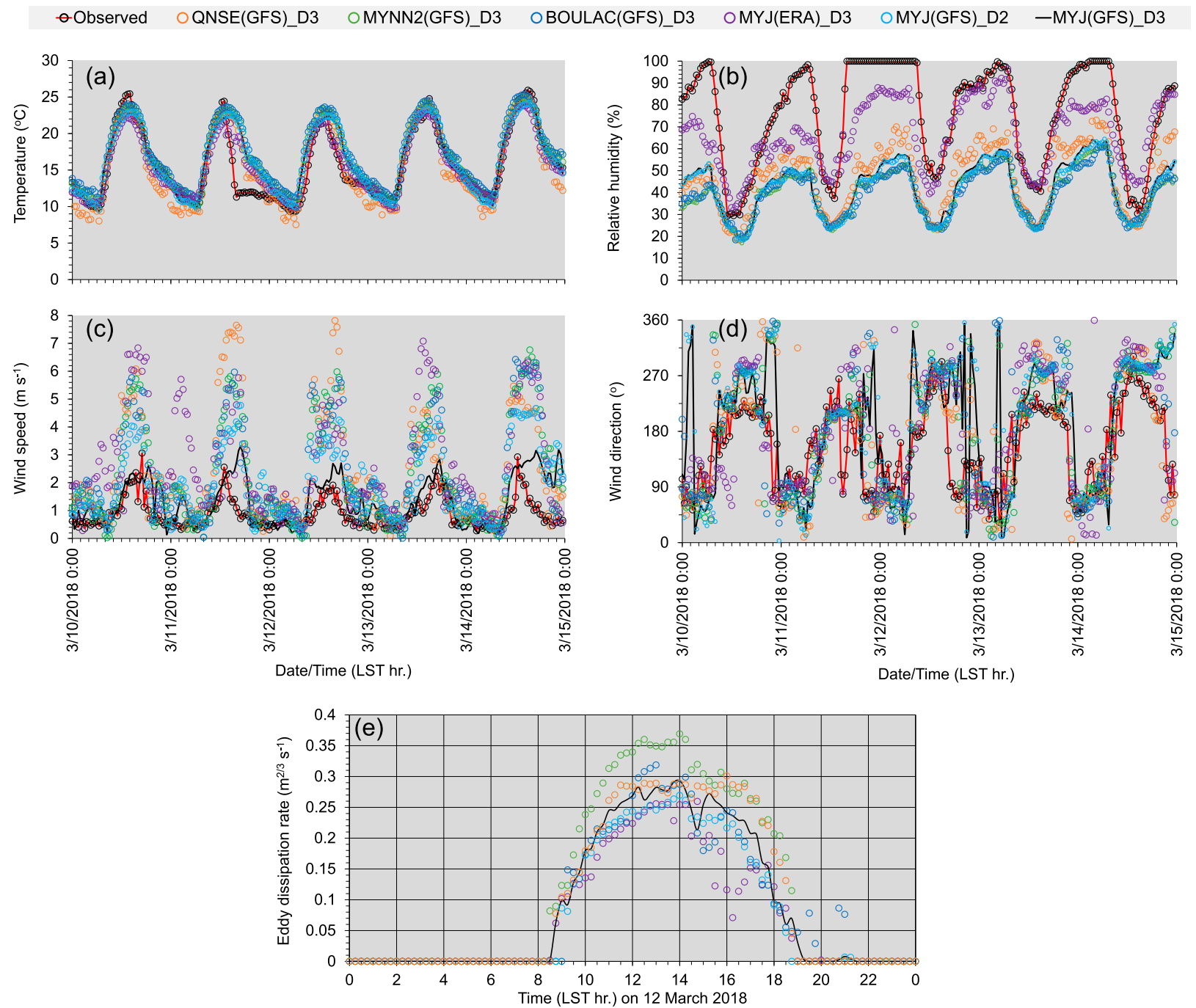

FIG. 7. Diurnal variation of (a) temperature at $2 \mathrm{~m} \mathrm{AGL,} \mathrm{(b)} \mathrm{relative} \mathrm{humidity} \mathrm{at} 2 \mathrm{~m}$ AGL, and (c) wind speed at $10 \mathrm{~m}$ AGL from 10 to 15 Mar 2018 at the TIA from output generated by different case simulations during the sensitivity study. (e) As in (a)-(d), but for at $90 \mathrm{~m}$ AGL on 12 Mar 2018. Please refer to Table 3 for the sensitivity experiments.

for temperature prediction for all the cases. Humidity, on the other hand, shows good correlation but appears largely negative biased, consistent to the original forecast. Similarly, wind speed show relatively poor $R$ and large bias and error. Though the wind direction has the poorest correlation, the $B_{\mathrm{NMBF}}$ and $E_{\mathrm{MAEF}}$ are better compared with the case of humidity and wind speed.

The correlation coefficient $R$ between observed and predicted values for temperature $(\sim 0.89-0.92)$, relative humidity $(\sim 0.80-0.83)$, wind speed $(\sim 0.54-0.87)$ and wind direction $(\sim 0.27-0.38)$ with different PBL schemes for GFS initialized simulations and an ERA-I initialized MYJ hindcast show very close value. This little variability in $R$ in each group suggests a consistent prediction of diurnal variation for the parameters that can also be inferred from Fig. 7.
Likewise, MB in all cases of humidity (from $-6.89 \%$ to $-33.77 \%$ ) is negative biased while they are positive biased for wind speed $\left(\sim 0.43-1.5 \mathrm{~m} \mathrm{~s}^{-1}\right)$ and direction $\left(\sim 7.64^{\circ}-37.14^{\circ}\right)$. All simulations but MYJ (ERA-I) (from $-0.31^{\circ}$ to $1.61^{\circ} \mathrm{C}$ ) show positive bias for temperature. The effect of negative bias in temperature by MYJ (ERA-I) can be seen in the marked decrease in the MB in relative humidity and improvement in humidity prediction (see Figs. $7 \mathrm{~b}$ and $8 \mathrm{~b}$ ).

For wind speed, all other PBL schemes and even MYJ (ERA-I) significantly overestimated wind speed during daytime (see Fig. 7c). Because of the overestimated wind speed an increased EDR for the cases of BouLac, MYNN2, and MYJ (ERA-I) might be expected. In Fig. 7e, EDR for BouLac and MYNN2 is higher by 
(a)

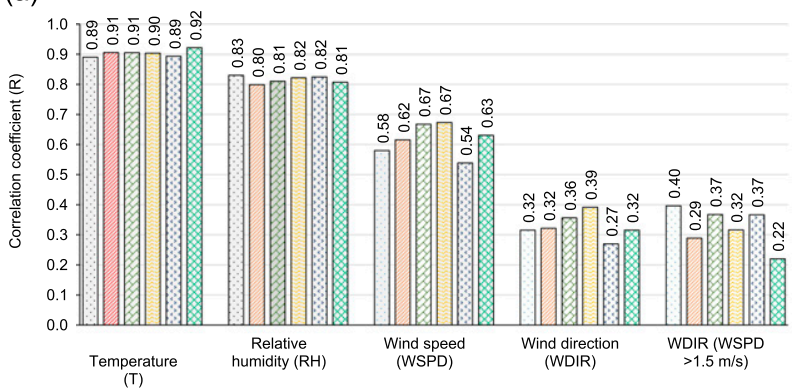

LEGEND
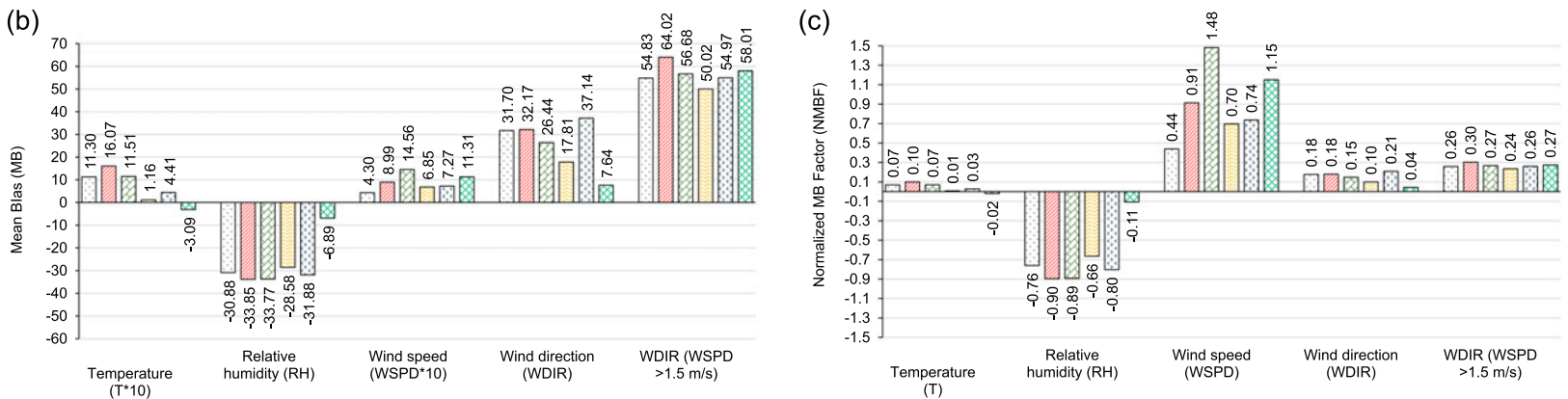

(d)
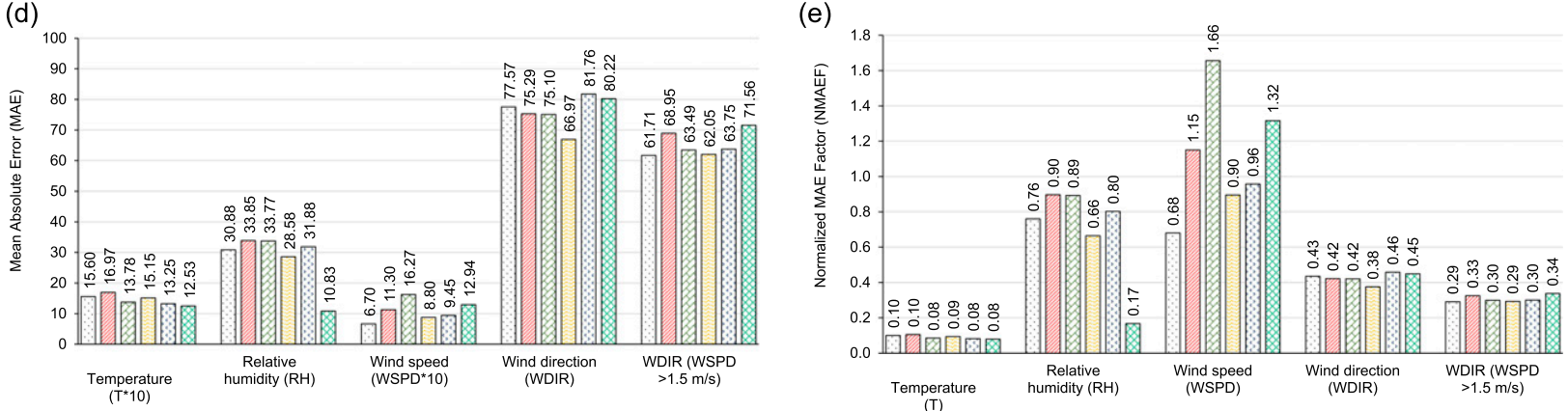

FIG. 8. Composite graph plots comparing the (a) correlation coefficients, (b) mean bias, (c) normalized mean bias factor, (d) mean absolute error, and (e) normalized mean absolute error factor for temperature, relative humidity, wind speed, and wind direction for observed speed more than $1.5 \mathrm{~m} \mathrm{~s}^{-1}$ generated by different simulations during the sensitivity study. Note that mean bias and mean absolute error of temperature and wind speed in (b) and (d) have been multiplied by 10 for better visualization of the bars. Please refer to Table 3 for the sensitivity study.

almost 2 times during day time but EDR for MYJ (ERA-I) is very close to the MYJ (GFS) despite the increased wind speed and that for QNSE (GFS) is comparable to MYJ (GFS) and MYJ (ERA-I).

Like $R$ and MB, MAE also show only little variation in each group (temperature: $\sim 0.13^{\circ}-0.17^{\circ} \mathrm{C}$, relative humidity: $\sim 10.83 \%-33.85 \%$, wind speed: $\sim 0.67-0.16 \mathrm{~m} \mathrm{~s}^{-1}$, and wind direction: $\sim 73.77^{\circ}-90.51^{\circ}$ ).

A similar tendency of $R$, bias, and error in almost all GFS initialized simulations suggests a more or less consistent pattern of near-surface atmospheric conditions including turbulence. However, among the cases initialized with GFS, statistics suggest that QNSE outperforms prediction of temperature, relative humidity, and wind direction compared to other PBL options as indicated by a relatively low value of MB. Similarly, between GFS and ERA-I initialized simulation with the MYJ PBL scheme, the latter performs better except for wind speed. Thus, global initialization data from ECMWF with QNSE could be a better combination for routine forecast over the region if the overestimation of wind speed is to be ignored.

On comparing the D2 near-surface variable with that of D3, temperature is less biased for coarse resolution (D2), else the correlation is decreased and errors are increased, more significantly in wind speed (see Figs. $8 \mathrm{~b}, \mathrm{~d}$ and $7 \mathrm{c}$ ). It should be noted that, despite the major indifference between prediction of basic meteorological parameters by $\mathrm{D} 2$ and $\mathrm{D} 3$, the $3-\mathrm{km}$ resolution does not appear enough to capture minor turbulence 
characters compared to the $1-\mathrm{km}$ resolution (figure not shown) as a result of averaging out in the coarse grid. It is expected to require 1-km or finer grid resolution for operational forecasts, particularly, for aviation safety purposes.

The reasonable degree of consistencies in the diurnal variation of the basic variables like temperature, relative humidity, wind direction, wind speed, and the EDR between different sensitivity cases discussed above and with the observations discussed in section 4 a suggests that the prediction of the WRF routine forecast at the third domain better serves for the discussion of the nearsurface wind characteristics and atmospheric turbulence on the day of UBG-211 accident.

\section{c. Local flow characteristics}

Regional-scale flows developed under synoptic conditions are typically modified into mesoscale local flows over the complex mountainous terrain (Ekhart 1948; Bossert and Cotton 1994a,b). When impacted by intrinsic surface forcing, these mesoscale local flows often lead to the formation of unexpectedly hazardous conditions for low-level aviation activities (Fahey et al. 2006). The midhills of the central Nepal Himalayan region are complex enough to develop their own characteristic mesoscale local flows. Because local flows are largely responsible for the state of the immediate atmosphere over the area, their spatial and temporal distributions over the Kathmandu Valley are discussed in this subsection during the time of the accident.

While the wind at $500 \mathrm{hPa}$ appears predominantly northwesterly at speeds greater than $12 \mathrm{~m} \mathrm{~s}^{-1}$ throughout the day, the near-surface winds were typical with a diurnal variation determined by characteristic surface forcing. However, during the time of the accident, wind speed at $500 \mathrm{hPa}$ increased to $15 \mathrm{~m} \mathrm{~s}^{-1}$ (see Fig. 6b).

Figures $9 \mathrm{a}-\mathrm{d}$ present the diurnal wind distribution at about $27 \mathrm{~m}$ AGL at four representative times on 12 March 2018. A short yellow line in the middle of the figures represents the approximate length and orientation of TIA. The blue line in Fig. 9c shows the approximated path drawn with reference to the DFDR derived flight path shown in Fig. 2a. The points labeled from "1" to " 6 " marked on the line are the locations where the diurnal variation of EDR is discussed in subsection 4d.

Figure 9a elucidates the presence of a calm situation with wind speed less than $0.5 \mathrm{~m} \mathrm{~s}^{-1}$ under a stably stratified atmosphere over the valley floor at 0500 LST. The vertical cross-sectional plot of wind (see Fig. 10a) along a southwest-northeast line (see the red line $\mathrm{AB}$ in Fig. 9b) at 0500 LST suggest the presence of highly stratified conditions up to $200 \mathrm{~m}$ AGL as signified by increased potential temperature in the layer. Until
0730 LST appreciable drainage flow of about $1 \mathrm{~m} \mathrm{~s}^{-1}$ prevailed along the Bagmati River gorge leading to the southern plains and in the western pass toward the western neighboring valley (figure not shown).

At approximately 0815 LST, influenced by solar heating, the drainage winds along the river gorge and the western pass vanished with wind emerging toward the Kathmandu valley. The southwesterly upvalley wind with speed as much as $7 \mathrm{~m} \mathrm{~s}^{-1}$ intruded into the valley via the Bagmati River gorge and by 1015 LST covered the eastern half of the valley (see Fig. 9b). Meanwhile, strong thermal convection developed over the Kathmandu Valley as indicated by the uplifted early morning nearsurface stable layer to a height of $\sim 2 \mathrm{~km}$ MSL (see Fig. 10b). Near this time, cumulus clouds over the surrounding mountaintops (see Fig. 5a) are thought to have developed due to the condensation of water vapor lifted by a strong updraft. The updraft was caused by the convergence of prominent upslope winds over the mountain ridges. The pattern of simulated spatial distribution of high relative humidity at $625 \mathrm{hPa}$ (see Fig. 5b) may justify the mechanism of formation and the pattern of clouds seen in the satellite picture (see Fig. 5a).

The presence of the Mt. Nagarjuna (see Fig. 1a for location) in the western rim of the valley effectively blocked the westerly wind and forced it to bifurcate and channel through the low-mountain passes to its northern and southern sides while intruding into the Kathmandu Valley. The bifurcated westerly merged again into a northwesterly over the west-central portion of the valley. This northwesterly wind system, as it advanced, converged with the southwesterly, and the southwesterly gradually formed into a banana-like shape (see Figs. 9bd). As a result, a strong crosswind prevailed over the TIA airfield. Most importantly, depending upon the strength of the southwesterly and northwesterly winds, the convergence line of these two major wind systems repeatedly crossed the TIA possibly generating strong updrafts and turbulence in and around the airfield.

The vertical cross-sectional plots of winds and potential temperature approximately along the TIA airfield (see the line $A B$ in Fig. 9b), revealed that the nighttime stably stratified near-surface atmosphere of the Kathmandu Valley (see Fig. 10a) began to dissipate at about 0815 LST (not shown). By 1015 LST the combined upslope/valley and the plane-to-plateau wind started penetrating the valley via the western low mountain passes and the river gorge in the southwestern rim of the valley (see Figs. 9b and 10b) as described in previous studies (Regmi et al. 2003; Panday et al. 2009; Regmi and Maharjan 2015; Regmi et al. 2019). Later in the afternoon, particularly, during the period of the aircraft accident (see Figs. 9c 

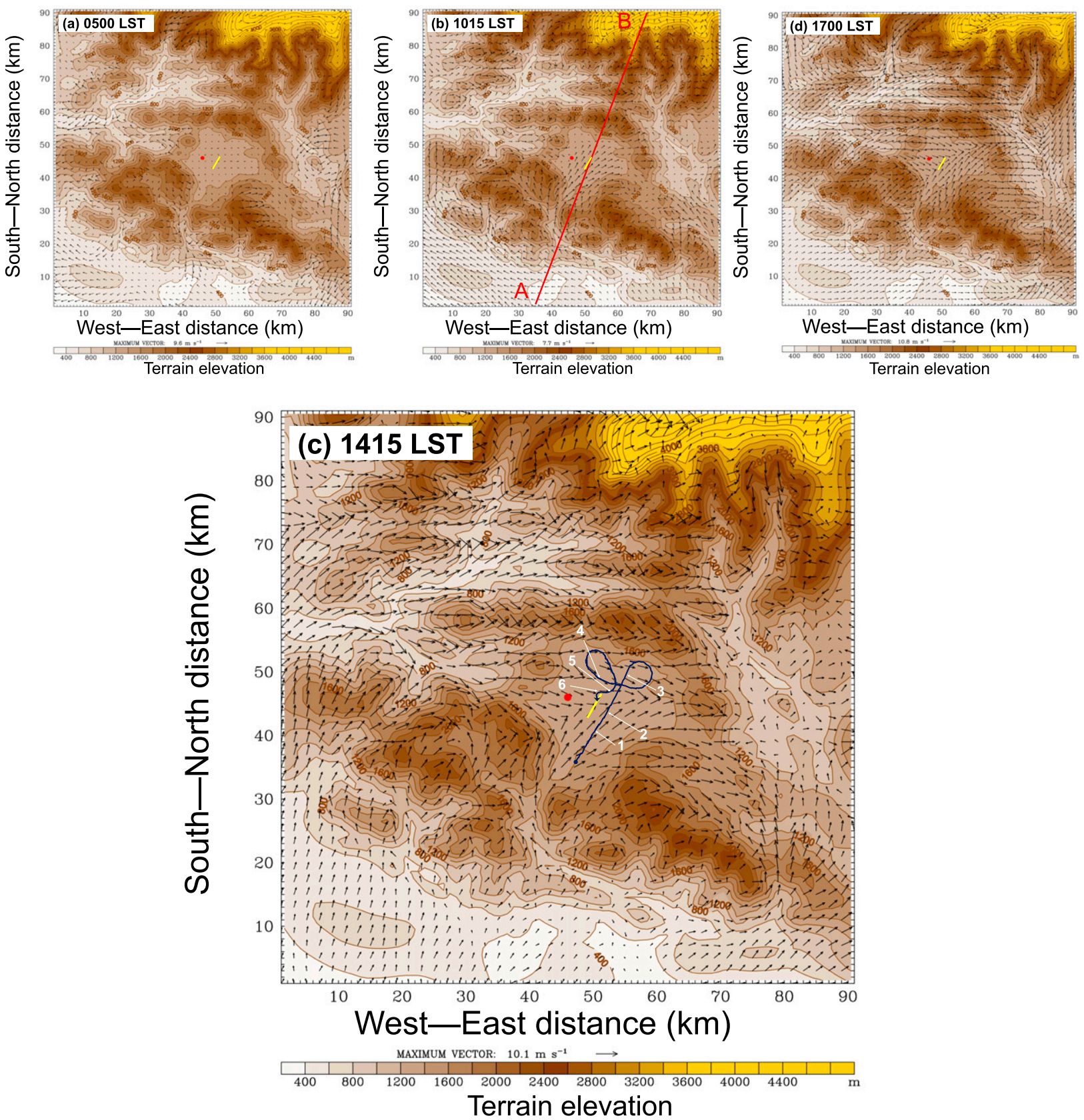

FIG. 9. Spatial distribution of near-surface wind over the Kathmandu Valley at $27 \mathrm{~m}$ AGL at (a) 0500, (b) 1015, (c) 1415, and (d) 1700 LST. The short yellow line at the central area of the valley shows the approximate length and orientation of the TIA airfield. Along the southwest-northeast line labeled A-B in (b), the vertical cross-sectional distribution of winds is discussed. The blue line in (c) indicates the approximate path followed by the UBG-211 over the valley and points labeled 1-6 in white denote locations where time series of EDR have been studied (see Fig. 12).

and 10c) the southwesterly-northwesterly convergence described above crossed the TIA airfield. This led to the development of highly complex airflow dynamics including strong up- and downdrafts along the approach to the TIA.

Examining the series of WRF-ARW predicted vertical wind fields in 15-min intervals, it can be said that during approach and while holding over the Kathmandu
Valley, the valley was experiencing strong downdrafts over the southern part, updrafts over the central part and downdrafts in the northern part of the valley. These conditions formed vertically oriented air rotational patterns with vertical wind speeds as great as $1 \mathrm{~m} \mathrm{~s}^{-1}$ over the TIA airfield (see Fig. 10c). The updrafts generated by the convergence of the northwesterly and 

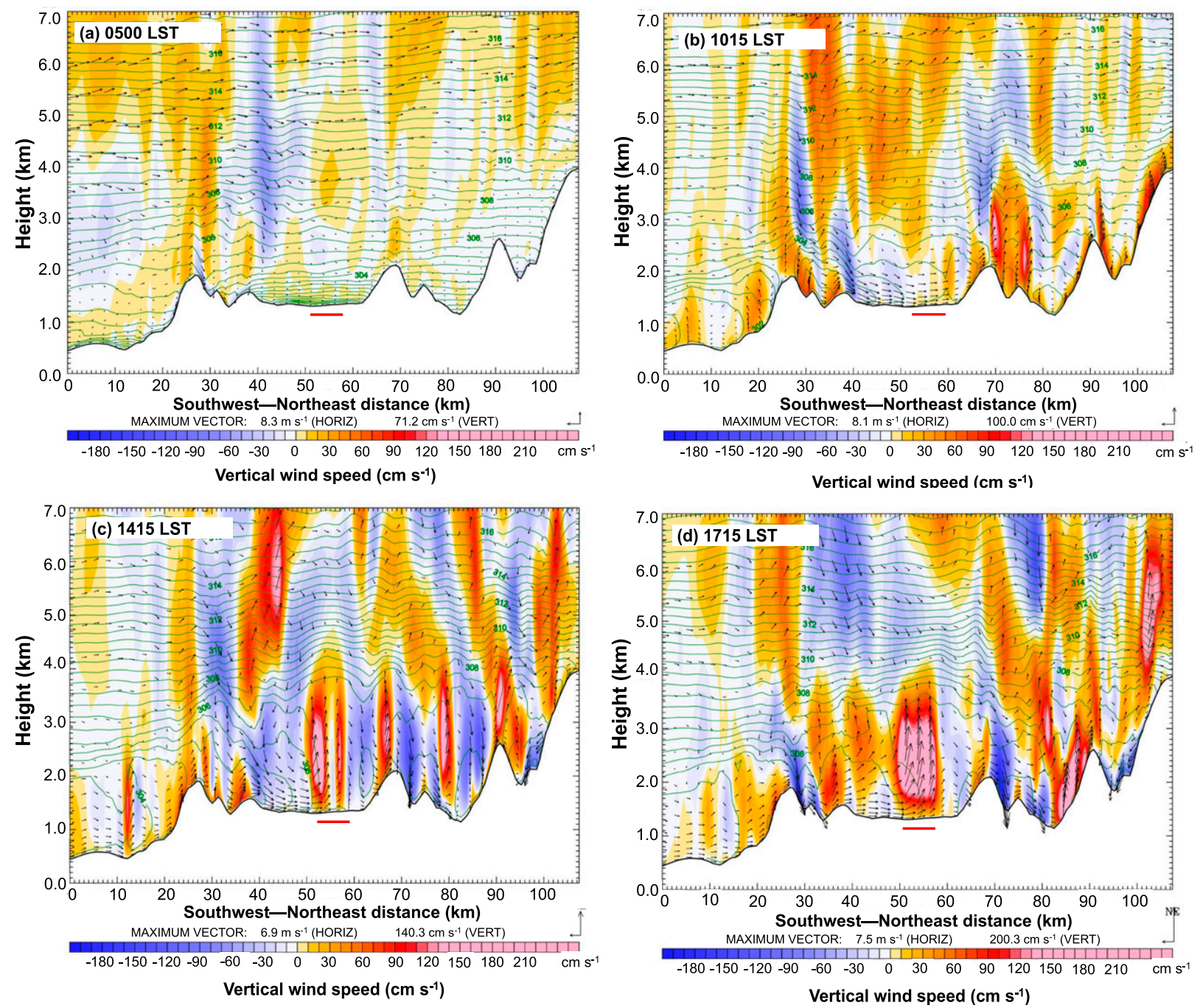

FIG. 10. Composite cross-sectional plot of wind vectors (vectors), vertical winds (colored contours), and the potential temperature (lines) along the southwest-northeast line A-B (see Fig. 9b) at the representative time mentioned at the top-left corner of each panel. The short red line indicates the approximate location of the TIA airfield.

southwesterly winds combined with the convergence of the bifurcated westerly wind over the western part of the valley may have been manifest as a long strip of convective clouds extending west to east in the central area of the valley (see Fig. 5c). The strong updraft over the central area of the valley continued till the late afternoon (see Fig. 10d). These updrafts appear to induce a subsidence, with a speed of $0.5 \mathrm{~m} \mathrm{~s}^{-1}$, traveling from as high as $6 \mathrm{~km}$ MSL and generating a vertical rotor in the southern part of the valley. The subsidence region from 40 to $50 \mathrm{~km}$ and from 58 to $63 \mathrm{~km}$ in the horizontal scale of Fig. 10c appears cloud free (see Fig. 5c), as would be expected.

It also appears that, during the afternoon, a westerly crosswind prevailed over the TIA airfield with occasional dominance of a southwesterly tailwind on runway 02 for the southern half of the runway. This is potentially relevant for UBG-211 because the aircraft would have had to traverse two convergence zones during its final moments of flight. While the surface wind was apparently mild, as per the measurements and predictions, the prevalence of significant wind shear and turbulence over the TIA airfield can be expected and may have contributed to the incident as the aircraft was approaching at critically low altitude after executing a hold. These conditions can be identified in Figs. 6a and 10c. The surface wind speed is reduced to around $3.5 \mathrm{~m} \mathrm{~s}^{-1}$ and winds at $1.3 \mathrm{~km} \mathrm{AGL}$ are dominated by the northwesterly with a speed of nearly $5 \mathrm{~m} \mathrm{~s}^{-1}$ throughout the valley. 


\section{d. Turbulence characteristics}

To further evaluate potential impacts of atmospheric turbulence challenging the aircraft, wind shear, Richardson number (Ri), TKE, and EDR (Kim et al. 2014; Kim and Chun 2010; Regmi et al. 2017; Sharman et al. 2012; Fahey et al. 2006) were investigated. In this subsection, these parameters are evaluated and their possible implications for the UBG-211 aircraft accident is examined.

Wind shear, according to International Civil Aviation Organization (ICAO), refers to change in wind speed and/or direction in space (horizontal or vertical direction), including updrafts and downdrafts (ICAO 2005). Aircraft encountering wind shear may suddenly lose or gain speed and altitude. The effect of wind shear is particularly dangerous when an aircraft is operating at a low altitude (McCann 1999). Figure 11a shows the spatial distribution of horizontal bulk wind shear over the Kathmandu Valley calculated between surface and $3 \mathrm{~km}$ AGL at $1415 \mathrm{LST}$. Over runway 02 and in the south/southeastern part of the valley, the wind shear varies from 5 to $8 \mathrm{~m} \mathrm{~s}^{-1}$. In reference to the DFDR path (see Figs. 2a and 9c) and spatial distribution of wind shear (see Fig. 11a), though the plane made its final approach from an apparently low wind shear region, it, unfortunately, landed $1700 \mathrm{~m}$ from the threshold for runway 02 , which brought it through regions of significant wind shear during its final approach.

To further estimate the turbulence, the spatial and temporal distribution of the total energy possessed by the turbulent part of the wind velocity, that is, TKE in the lower atmospheric layer over the valley was calculated. The diurnal horizontal spatial distribution of TKE at $250 \mathrm{~m}$ AGL suggests the near-surface atmosphere over the valley started becoming turbulent with TKE more than $1.2 \mathrm{~J} \mathrm{~kg}^{-1}$ as early as $1100 \mathrm{LST}$ (not shown). Two distinct turbulent zones having TKE around $2.5 \mathrm{~J} \mathrm{~kg}^{-1}$ cross the airport during the landing period of the aircraft (see Fig. 11c). Similarly, a vertical cross section of TKE at the same time (see Fig. 11d) also shows the turbulent region with values for TKE as much as $2.1 \mathrm{~J} \mathrm{~kg}^{-1}$ extending to $1.5 \mathrm{~km}$ AGL over the northern part of the TIA airfield and beyond.

To quantify the turbulence severity, EDR was calculated using Eq. (6) with TKE and eddy length $L_{E}$ (Ahmad and Proctor 2012; Regmi et al. 2017; Pokharel et al. 2017).

$$
\mathrm{EDR}=\left[0.238(\mathrm{TKE}-0.1)^{3 / 2} / L_{E}\right]^{1 / 3} .
$$

The severity of atmospheric turbulence with respect to EDR values are categorized as "smooth to light," "light," "light to moderate," "moderate," "moderate to severe," and "severe" for medium-size aircraft with EDR thresholds of $0.014,0.050,0.125,0.220,0.350$, and $0.500 \mathrm{~m}^{2 / 3} \mathrm{~s}^{-1}$, respectively (Sharman et al. 2014; Strauss et al. 2015; Pokharel et al. 2017). Similarly, the Aviation Weather Center (AWC) defines "moderate" and "severe" turbulence with EDR thresholds of 0.2 and $0.44 \mathrm{~m}^{2 / 3} \mathrm{~s}^{-1}$, respectively, for medium aircraft (AWC 2019). From the horizontal spatial distribution of EDR at $90 \mathrm{~m}$ AGL (see Fig. 11e), and its vertical cross-sectional distribution along the TIA runway (see Fig. 11f), it can be seen that the EDR was around $0.26 \mathrm{~m}^{2 / 3} \mathrm{~s}^{-1}$ over the southern, $0.27 \mathrm{~m}^{2 / 3} \mathrm{~s}^{-1}$ in the middle, and $0.28 \mathrm{~m}^{2 / 3} \mathrm{~s}^{-1}$ at the northern end areas of the airfield. The EDR of this strength lies in the moderate turbulence for the mediumsize aircraft like DHC-8-402 in both the categorization mentioned above.

To better reveal the turbulence experienced by the UBG-211 from approach to landing course, time series of EDR at $90 \mathrm{~m}$ AGL (see Fig. 12) were examined at six representative locations along the approximate path followed (see points labeled 1-6 in Fig. 9c). In the subplots of Fig. 12, the shaded region indicates the range of moderate turbulence for medium size aircraft (Sharman et al. 2014; Strauss et al. 2015; Pokharel et al. 2017) and the vertical black dashed line indicates the EDR at the time of the accident ( $\sim 1415$ LST). The diurnal variations of EDR suggest that the near-surface valley atmosphere became moderately turbulent $\left(\mathrm{EDR}>0.22 \mathrm{~m}^{2 / 3} \mathrm{~s}^{-1}\right)$ as early as 1100 LST and was sustained for several hours.

The time series plots show that when the aircraft was approaching (points 1 and 2) it passed through the locations with EDR of $\sim 0.277$ and $\sim 0.230 \mathrm{~m}^{2 / 3} \mathrm{~s}^{-1}$ (see Figs. 12a,b) whereas, on hold, EDR varied from $\sim 0.236 \mathrm{~m}^{2 / 3} \mathrm{~s}^{-1}$ in the northeastern part (point 3) to $\sim 0.297 \mathrm{~m}^{2 / 3} \mathrm{~s}^{-1}$ in the northwestern part (point 4) of the valley (see Figs. 12c,d). Over the areas from where the aircraft attempted the final landing (points 5 and 6 ) the EDR remained $\sim 0.274$ and $\sim 0.277 \mathrm{~m}^{2 / 3} \mathrm{~s}^{-1}$ (see Figs. 12e,f). Thus, it appears that the near-surface atmosphere of the valley along the path followed by the aircraft can be considered significantly turbulent and potentially hazardous.

To further examine if the atmosphere over the airfield could have sustained the turbulent condition, $\mathrm{Ri}$, the ratio of static stability to vertical wind shear (Widseth and Morss 1999) in Eq. (7), has been evaluated in the vertical cross section along the TIA (see Fig. 11b). Ri is mathematically expressed as

$$
\mathrm{Ri}=\frac{\left(\mathbf{g} / \overline{\theta_{v}}\right)\left(\partial \overline{\theta_{v}} / \partial z\right)}{\left[(\partial \overline{\mathbf{U}} / \partial z)^{2}+(\partial \overline{\mathbf{V}} / \partial z)^{2}\right]},
$$

where $\mathbf{g}$ is the acceleration due to gravity, $\overline{\theta_{v}}$ is the average virtual potential temperature, $\overline{\mathbf{U}}$ is the average 

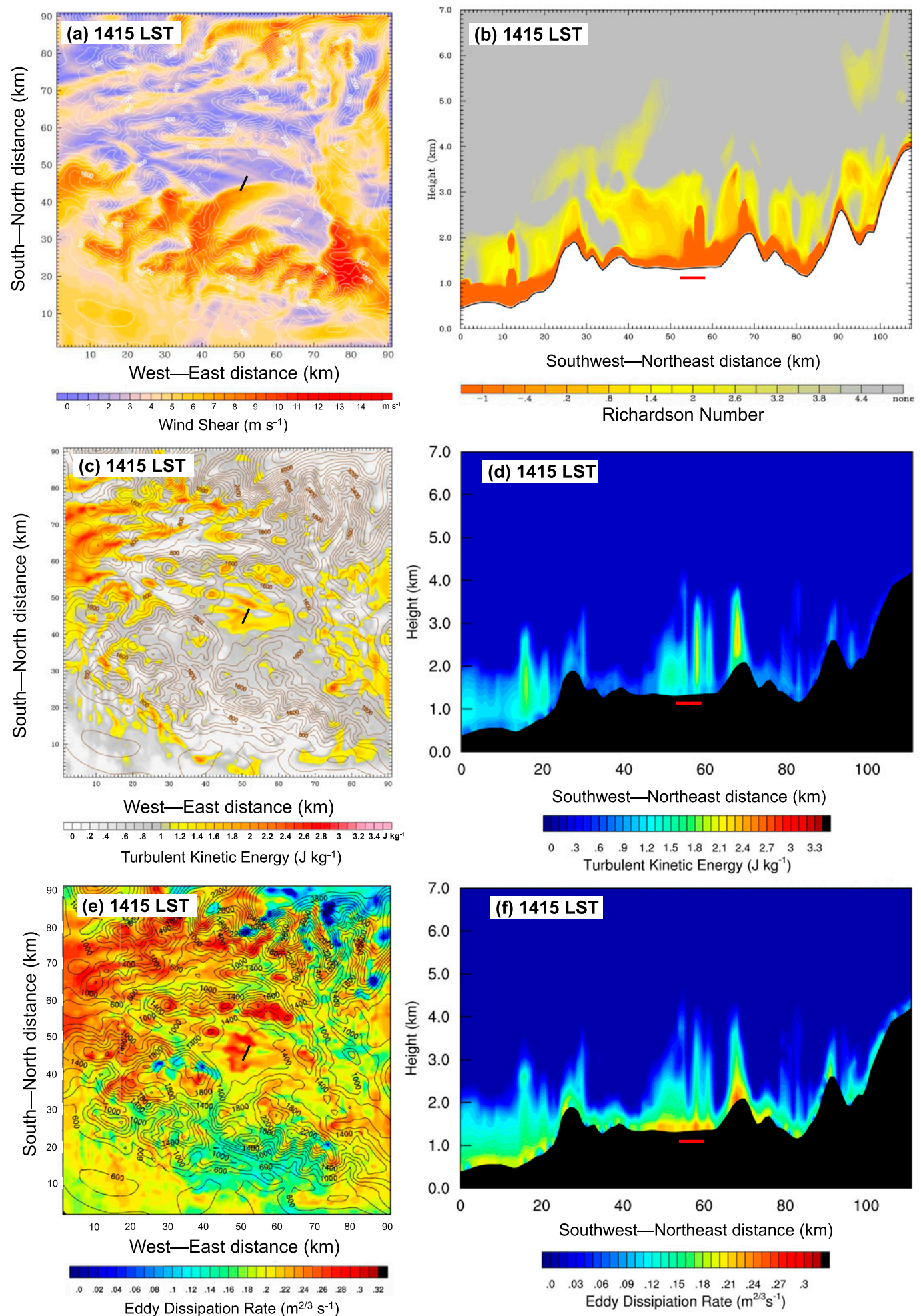

FIG. 11. Spatial distribution of (a) horizontal bulk wind shear, (b) vertical cross section of the Richardson number, (c) spatial distribution of TKE at a height of $250 \mathrm{~m} \mathrm{AGL,} \mathrm{(d)} \mathrm{its} \mathrm{corresponding} \mathrm{vertical} \mathrm{cross} \mathrm{section,} \mathrm{(e)} \mathrm{spatial}$ distribution of EDR at a height of $90 \mathrm{~m}$ AGL, and (f) its vertical cross section. The vertical cross sections are along line A-B shown in Fig. 9b. All the figures are at 1415 LST. 

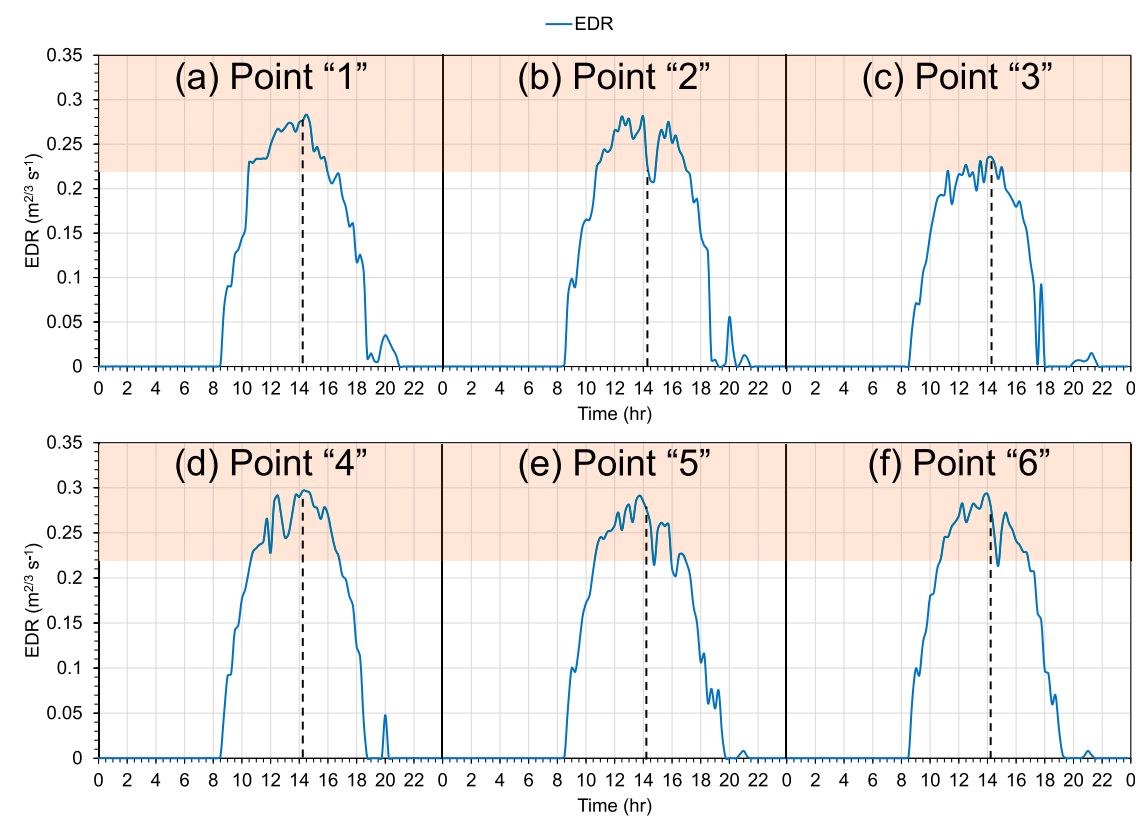

FIG. 12. Diurnal variation of EDR at $90 \mathrm{~m} \mathrm{AGL}$ at six points along the UBG-211 flight path (see Fig. 9c) over the Kathmandu Valley on 12 Mar 2018. The vertical dashed line at 1415 LST shows the EDR value around the time of the accident.

wind velocity component along the east, $\overline{\mathbf{V}}$ is the average wind velocity component along the north, and $z$ is the vertical coordinate (Stull 1988).

Theoretically, the atmosphere becomes unstable and favors turbulence when $\mathrm{Ri}$ is less than 0.25 (Lyons et al. 1964; Taylor 1931). The atmosphere becomes highly unstable (turbulent) when $\mathrm{Ri}$ is negative. Negative Ri results only when the vertical gradient of potential temperature is negative. $\mathrm{Ri}$ calculated over the valley appears as low as -1 in the atmosphere close to the surface from about 1000 LST (not shown). Later in the afternoon, while the aircraft was approaching, holding, and landing, it extended vertically to about $300 \mathrm{~m}$ AGL throughout the valley floor and up to $1.5 \mathrm{~km}$ AGL over the TIA airfield (see Fig. 11b). The spatial and temporal distributions of Ri, thus, suggest that the near-surface atmosphere over the valley was in a condition to sustain the turbulence.

\section{Meteorological implications}

This section explores the possible links between the predicted atmospheric situations over the Kathmandu Valley and the fatal crash of UBG-211 aircraft at the TIA. As per the flight history, the aircraft entered into the valley via the southern gateway at about 1410 LST, when a prominent southwesterly tailwind of $6-7 \mathrm{~m} \mathrm{~s}^{-1}$ (see Fig. 9c) and horizontal wind shear of $8-9 \mathrm{~m} \mathrm{~s}^{-1}$ (see Fig. 11a) were prevalent over the southern part of the valley. During the period, the area was also suffering from strong subsidence of about $1 \mathrm{~m} \mathrm{~s}^{-1}$ and a vertical rotor (see Fig. 10c). While the characteristic tailwind should be familiar to a pilot regularly flying to the TIA, the complex dynamics and the turbulent situation that developed during the period could be unexpected. The aircraft at low altitude, flew pass the moderate turbulence region with an EDR of $\sim 0.27 \mathrm{~m}^{2 / 3} \mathrm{~s}^{-1}$ (see Fig. 11e) around point 1 (see Fig. 9c), and then perhaps misaligned to the TIA. It further proceeded toward the northeast from about $\sim 2 \mathrm{~km}$ east parallel to the runway, made a right round in the northeastern region, and headed toward the more turbulent northwestern part of the valley. The near-surface atmosphere along the path followed by the aircraft from point 2 to 3 and the northeastern region appears relatively less turbulent with respective EDR values of 0.230 and $0.236 \mathrm{~m}^{2 / 3} \mathrm{~s}^{-1}$ at points 2 and 3 , wind shear less than $2 \mathrm{~m} \mathrm{~s}^{-1}$, and a mild westerly crosswind. Reaching the northwestern area around point 4 , the aircraft appears to have entered into the region of moderate turbulence (EDR $\sim 0.29 \mathrm{~m}^{2 / 3} \mathrm{~s}^{-1}$, TKE $\sim 2.1 \mathrm{~J} \mathrm{~kg}^{-1}$, wind shear $4-5 \mathrm{~m} \mathrm{~s}^{-1}$ ) and northwesterly head wind. Overcoming the situation, it made another right round over the northwestern part of the valley and proceeded east for the final landing. As it approached runway 20 via point 5 , it was under the influence of turbulent near-surface wind with an EDR of $0.27-0.28 \mathrm{~m}^{2 / 3} \mathrm{~s}^{-1}$, a westerly crosswind of $4-5 \mathrm{~m} \mathrm{~s}^{-1}$ (see Fig. 9c), and a strong 
downdraft of $0.5 \mathrm{~m} \mathrm{~s}^{-1}$ (see Fig. 10c). Under these conditions, it failed to establish a proper alignment with the runway and traversed farther to the west at point 6 . While trying to realign, the plane might have made a sharp left turn with a bank angle around $40^{\circ}$ (AIC 2018). The large bank angle together with the increased surface area for a westerly crosswind at $4-5 \mathrm{~m} \mathrm{~s}^{-1}$ may have further contributed to the improper alignment in its final approach. The severity of the turbulence in the region is well reflected by values of EDR of $0.27-0.28 \mathrm{~m}^{2 / 3} \mathrm{~s}^{-1}$, TKE $\sim 2.1 \mathrm{~J} \mathrm{~kg}^{-1}$, and Ri of -1 . Moreover, the aircraft could have also faced the challenges of altitudinal loss and gain within the horizontal distance of a few hundred meters over the runway due to the prevalence of strong up- and downdrafts of around $1 \mathrm{~m} \mathrm{~s}^{-1}$ and wind shear of 5-7 $\mathrm{m} \mathrm{s}^{-1}$. Indeed, the survivors described violent shakes and ultimately skidding off to the east of the runway. In consideration of the above discussed consistencies between the flight behavior (as revealed by DFDR (AIC 2018) and survivors narration) and the predicted nearsurface atmospheric conditions, it can be argued that the contribution of meteorological conditions for the fatal aircraft accident cannot be ignored.

\section{Conclusions}

The tragic accident of US-Bangla aircraft (UBG-211) on 12 March 2018 at the TIA, Kathmandu was reported to have no contribution from the meteorological factors based on METAR and some ground observations. The WRF-ARW weather forecast for the region, however, clearly reveals the presence of critically hazardous meteorological situations over the TIA airfield during its landing. The value of turbulent parameters, $2.5 \mathrm{~J} \mathrm{~kg}^{-1}$ of TKE, $5-8 \mathrm{~m} \mathrm{~s}^{-1}$ of wind shear, around $0.26-0.29 \mathrm{~m}^{2 / 3} \mathrm{~s}^{-1}$ of EDR, and a Richardson number equal to -1 , during the time of the accident, signify the presence of sufficient turbulent conditions over the valley. The spatial distribution of wind flow showed a number of wind convergence zones in the valley crossing the TIA. The UBG-211 had to sustain such turbulent conditions while holding and during landing attempts. Arguable consistencies between the flight behavior and the forecasted near-surface flow fields and turbulence can be seen. Thus, while the lack of situational awareness and the communication gap between the ATC and PIC might have had some impact, the sudden rise and drop of altitude while encountering the respective up- and downdrafts and the eventual misalignment of the aircraft under the prevailing westerly crosswind might also have played some role leading to a fatal accident.

The performance of the WRF-ARW routine forecast was examined against observations and hindcast sensitivity runs with the TKE-resolving PBL schemes, global initialization data, and horizontal grid resolutions. It is found that the routine forecast was fairly good for wind and temperature during the clear weather situations but remained rather poor during heavily cloudy events. In the forecast, primarily, the near-surface relative humidity was largely and systematically underpredicted. The negative bias and MAE of the humidity, however, decreased producing an appreciable improvement in the humidity prediction, when initialized with the ERA-I data. A partial contribution to the humidity improvement in the ERA-I run is due to the cold temperature bias, in contrast to the warm bias in GFS runs. The routine forecast with the MYJ scheme and initialized with GFS data tended to represent the mean turbulent wind characteristics predicted with BouLac, MYNN2, and QNSE PBL schemes. The WRF-ARW forecast of surface variables remained almost the same for the finest domain $(1 \mathrm{~km} \times 1 \mathrm{~km}$ grid size $)$ and the coarse $(3 \mathrm{~km} \times$ $3 \mathrm{~km}$ grid size). However, the near-surface turbulence pattern appears better resolved in the finest domain, which can be crucial for safe LTO operation over the TIA.

The uncertainty statistics suggest that the ERA-I initialized WRF-ARW tended to improve the forecast of the surface atmosphere. Meanwhile, the QNSE PBL schemes among GFS runs showed the least bias in temperature, humidity, and wind direction. However, varied case studies are desired to find a preferable PBL scheme for the region. Finally, the range of uncertainties seen in the sensitivity analysis suggests that an ensemble approach accompanied by data assimilation from a good network of observation and nowcasting would be necessary for dependable forecasts for the TIA airfield. A customized numerical weather and boundary layer turbulence prediction system is highly desired for improved flight safety over the TIA.

Acknowledgments. We would like to acknowledge the Department of Environment, Ministry of Forests and Environment, and Department of Hydrology and Meteorology, Ministry of Energy, Water, and Irrigation, Government of Nepal for making data available for validation of the simulation output. We acknowledge the use of imagery from the NASA Worldview application (https://worldview.earthdata.nasa.gov/) operated by the NASA/Goddard Space Flight Center Earth Science Data and Information System (ESDIS) project. We are also thankful to Flightradar24 for permitting the use of the altitude graph of the UBG-211 aircraft. The data of the vertical sounding at Patna can be retrieved from the web database of University of Wyoming (http://weather.uwyo.edu/ upperair/sounding.html). We are also thankful to the 
University Grants Commission, Nepal for providing fellowship and research grant (Ph.D.-75/76-S\&T-17) to S. Shrestha for his Ph.D. study thereby enabling him to contribute in this paper. The authors, especially, would like to thank the anonymous reviewers and the editor for the suggestions and improvement in the paper.

\section{REFERENCES}

Ahmad, N., and F. Proctor, 2012: Estimation of eddy dissipation rates from mesoscale model simulations. 50th AIAA Aerospace Sciences Meeting Including the New Horizons Forum and Aerospace Exposition, Nashville, TN, American Institute of Aeronautics and Astronautics, AIAA 2012-0429, https:// doi.org/10.2514/6.2012-429.

AIC, 2018: Final report on the accident investigation of US-Bangla Airlines, Bombardier (UBG-211), DHC-8-402, S2-AGU, at Tribhuvan International Airport, Kathmandu, Nepal. Final report, Ministry of Culture, Tourism and Civil Aviation, The Government of Nepal, Kathmandu, 43 pp., https://reports.aviation-safety.net/ 2018/20180312-0_DH8D_S2-AGU.pdf.

AWC, 2019: Turbulence help. NOAA, accessed 24 April 2019, https://www.aviationweather.gov/turbulence/help?page = plot.

Barros, A., P. Shrestha, S. Chavez, and Y. Duan, 2018: Modeling aerosol-cloud-precipitation interactions in mountainous regions: Challenges in the representation of indirect microphysical effects with impacts at subregional scales. Rainfall-Extremes, Distribution and Properties, Intech Open, 23 pp., https://doi.org/ 10.5772/INTECHOPEN.80025.

Bossert, J. E., and W. R. Cotton, 1994a: Regional-scale flows in mountainous terrain. Part I: A numerical and observational comparison. Mon. Wea. Rev., 122, 1449-1471, https://doi.org/ 10.1175/1520-0493(1994)122<1449:RSFIMT>2.0.CO;2.

$\ldots$, and 1994b: Regional-scale flows in mountainous terrain. Part II: Simplified numerical experiments. Mon. Wea Rev., 122, 1472-1489, https://doi.org/10.1175/1520-0493(1994) $122<1472$ :RSFIMT $>2.0 . \mathrm{CO} ; 2$.

Chen, F., and J. Dudhia, 2001: Coupling an advanced land surfacehydrology model with the Penn State-NCAR MM5 modeling system. Part I: Model implementation and sensitivity. Mon. Wea. Rev., 129, 569-585, https://doi.org/10.1175/ 1520-0493(2001)129<0569:CAALSH > 2.0.CO;2.

Civil Aviation Authority of Nepal, 2018: Aviation safety report Civil Aviation Authority of Nepal. Final report, Civil Aviation Authority of Nepal, Kathmandu, 30 pp.

Cohen, A., S. Cavallo, M. Coniglio, and H. Brooks, 2015: A review of planetary boundary layer parameterization schemes and their sensitivity in simulating a southeast U.S. cold season severe weather environment. Wea. Forecasting, 30, 591-612, https://doi.org/10.1175/WAF-D-14-00105.1.

Collier, E., and W. W. Immerzeel, 2015: High-resolution modeling of atmospheric dynamics in the Nepalese Himalaya. J. Geophys. Res. Atmos., 120, 9882-9896, https://doi.org/10.1002/2015JD023266.

Dudhia, J., 1989: Numerical study of convection observed during the winter monsoon experiment using a mesoscale two-dimensional model. J. Atmos. Sci., 46, 3077-3107, https://doi.org/10.1175/ 1520-0469(1989)046<3077:NSOCOD>2.0.CO;2.

Ekhart, E., 1948: De la structure de látmospherÌ̀e dans la montagne. Meteorologie, 3, 3-26.

Emery, C., and E. Tai, 2001: Enhanced meteorological modeling and performance evaluation for two Texas ozone episodes. Texas
Natural Resource Conservation Commission, ENVIRON International Corporation, 235 pp., https://www.tceq.texas.gov/ assets/public/implementation/air/am/contracts/reports/mm/ EnhancedMetModelingAndPerformanceEvaluation.pdf.

Fahey, T. H., C. Shun, A. VanGerpen, J. Asano, and T. Nguyen, 2006: Low altitude wind shear hazards: Ground based detection and commercial aviation user needs. 12th Conf. on Aviation, Range, \& Aerospace Meteorology, Atlanta, GA, Amer. Meteor. Soc., 6.9, https://ams.confex.com/ams/pdfpapers/ 105361.pdf.

Hong, S.-Y., Y. Noh, and J. Dudhia, 2006: A new vertical diffusion package with an explicit treatment of entrainment processes. Mon. Wea. Rev., 134, 2318-2341, https://doi.org/10.1175/ MWR3199.1.

ICAO, 2005: Manual on low-level wind shear. Tech. Rep. Doc. 9817 AN/449, International Civil Aviation Organization, Montreal.

Jammalamadaka, S., and A. Sengupta, 2001: Topics in Circular Statistics. Series on Multivariate Analysis, Vol. 5, World Scientific, $336 \mathrm{pp}$.

Janjić, Z. I., 2001: Nonsingular implementation of the MellorYamada level 2.5 scheme in the NCEP Meso model. NCEP Office Note 437, 61 pp., https://www.emc.ncep.noaa.gov/ officenotes/newernotes/on437.pdf.

Karki, R., S. U. Hasson, L. Gerlitz, U. Schickhoff, T. Scholten, and J. Böhner, 2017: Quantifying the added value of convectionpermitting climate simulations in complex terrain: A systematic evaluation of WRF over the Himalayas. Earth Syst. Dyn., 8, 507-528, https://doi.org/10.5194/esd-8-507-2017.

Kim, J.-H., and H.-Y. Chun, 2010: A numerical study of clear-air turbulence (CAT) encounters over South Korea on 2 April 2007. J. Appl. Meteor. Climatol., 49, 2381-2403, https://doi.org/ 10.1175/2010JAMC2449.1.

,,-- R. Sharman, and S. B. Trier, 2014: The role of vertical shear on aviation turbulence within cirrus bands of a simulated western Pacific cyclone. Mon. Wea. Rev., 142, 2794-2813, https://doi.org/10.1175/MWR-D-14-00008.1.

Lyons, R., H. A. Panofsky, and S. Wollaston, 1964: The critical Richardson number and its implications for forecast problems. J. Appl. Meteor., 3, 136-142, https://doi.org/10.1175/15200450(1964)003<0136:TCRNAI > 2.0.CO;2.

McCann, D. W., 1999: A simple turbulent kinetic energy equation and aircraft boundary layer turbulence. Natl. Wea. Dig., 23, 13-19.

Mlawer, E. J., S. J. Taubman, P. D. Brown, M. J. Iacono, and S. Clough, 1997: Radiative transfer for inhomogeneous atmospheres: RRTM, a validated correlated-k model for the longwave. J. Geophys. Res., 102, 16663-16682, https://doi.org/ 10.1029/97JD00237.

Mughal, D. M., M. Lynch, F. Yu, B. McGann, F. Jeanneret, and J. Sutton, 2017: Wind modelling, validation and sensitivity study using weather research and forecasting model in complex terrain. Environ. Modell. Software, 90, 107-125, https:// doi.org/10.1016/j.envsoft.2017.01.009.

Panday, A. K., R. G. Prinn, and C. Schär, 2009: Diurnal cycle of air pollution in the Kathmandu valley, Nepal: 2. Modeling results. J. Geophys. Res., 114, D21308, https://doi.org/10.1029/ 2008JD009808.

Pokharel, B., B. Geerts, X. Chu, and P. Bergmaier, 2017: Profiling radar observations and numerical simulations of a downslope wind storm and rotor on the lee of the Medicine Bow Mountains in Wyoming. Atmosphere, 8, 39, https://doi.org/ 10.3390/atmos8020039.

Powers, J. G., and Coauthors, 2017: The Weather Research and Forecasting (WRF) model: Overview, system efforts, and 
future directions. Bull. Amer. Meteor. Soc., 98, 1717-1737, https://doi.org/10.1175/BAMS-D-15-00308.1.

Regmi, R. P., 2014a: Aviation hazards in the sky over Thada as revealed by meso-scale meteorological modeling. J. Inst. Sci. Technol., 19, 65-70, https://doi.org/10.3126/jist.v19i2.13854.

_ 2014b: Aviation hazards over the Jomsom airport of Nepal as revealed by numerical simulation of local flows. J. Inst. Sci. Technol., 19, 111-120, https://doi.org/10.3126/jist.v19i1.13836.

— over the Kathmandu valley, Nepal. Asia-Pac. J. Atmos. Sci., 51, 303-309, https://doi.org/10.1007/s13143-015-0078-1.

— , T. Kitada, and G. Kurata, 2003: Numerical simulation of late wintertime local flows in Kathmandu valley, Nepal: Implication for air pollution transport. J. Appl. Meteor., 42, 389-403, https:// doi.org/10.1175/1520-0450(2003)042<0389:NSOLWL>2.0.CO;2.

, _ _ J J. Dudhia, and S. Maharjan, 2017: Large-scale gravity current over the middle hills of the Nepal Himalaya: Implications for aircraft accidents. J. Appl. Meteor. Climatol., 56, 371-390, https://doi.org/10.1175/JAMC-D-16-0073.1.

, S. Maharjan, S. Shrestha, S. Shrestha, and G. Regmi, 2019: Wintertime boundary layer evolution and air pollution potential over the Kathmandu valley, Nepal. J. Geophys. Res. Atmos., 124, 4299-4325, https://doi.org/10.1029/2018JD030198.

Sharman, R., J. D. Doyle, and M. A. Shapiro, 2012: An investigation of a commercial aircraft encounter with severe clear-air turbulence over western Greenland. J. Appl. Meteor. Climatol., 51, 42-53, https://doi.org/10.1175/JAMC-D-11-044.1.

, L. Cornman, G. Meymaris, J. Pearson, and T. Farrar, 2014: Description and derived climatologies of automated in situ eddy-dissipation-rate reports of atmospheric turbulence. J. Appl. Meteor. Climatol., 53, 1416-1432, https://doi.org/ 10.1175/JAMC-D-13-0329.1.
Skamarock, W. C., and Coauthors, 2008: A description of the Advanced Research WRF version 3. NCAR Tech. Note NCAR/ TN-475+STR, 113 pp., https://doi.org/10.5065/D68S4MVH.

Strauss, L., S. Serafin, S. Haimov, and V. Grubišić, 2015: Turbulence in breaking mountain waves and atmospheric rotors estimated from airborne in situ and Doppler radar measurements. Quart. J. Roy. Meteor. Soc., 141, 3207-3225, https://doi.org/10.1002/ qj.2604.

Stull, R. B., 1988: An Introduction to Boundary Layer Meteorology. Kluwer Academic, 670 pp.

Taylor, G. I., 1931: Effect of variation in density on the stability of superposed streams of fluid. Proc. Roy. Soc. London, 132A, 499-523, https://doi.org/10.1098/RSPA.1931.0115.

Thompson, G., R. M. Rasmussen, and K. Manning, 2004: Explicit forecasts of winter precipitation using an improved bulk microphysics scheme. Part I: Description and sensitivity analysis. Mon. Wea. Rev., 132, 519-542, https://doi.org/10.1175/15200493(2004)132<0519:EFOWPU>2.0.CO;2.

Widseth, C. C., and D. A. Morss, 1999: Airborne verification of atmospheric turbulence using the Richardson number. Natl. Wea. Dig., 23, 39-44.

WMO, 2018: Guide to instruments and methods of observation, Vol. I-Measurement of meteorological variables. Tech. Rep. WMO-8, 548 pp., https://library.wmo.int/ index.php?lvl=notice_display\&id $=12407$.

Yu, S., B. Eder, R. Dennis, S.-H. Chu, and S. E. Schwartz, 2006: New unbiased symmetric metrics for evaluation of air quality models. Atmos. Sci. Lett., 7, 26-34, https://doi.org/10.1002/asl.125.

Zhang, H., Z. Pu, and X. Zhang, 2013: Examination of errors in near-surface temperature and wind from WRF numerical simulations in regions of complex terrain. Wea. Forecasting, 28, 893-914, https://doi.org/10.1175/WAF-D-12-00109.1. 